\title{
Mundo urbano y actividades económicas en la Rioja Alta bajomedieval
}

\author{
FCO. JAVIER GOICOLEA JULIÁN*
}

RESUMEN

A lo largo de los siglos medievales, en las ciudades y villas de La Rioja Alta se desarrollan toda una serie de actividades económicas que son el soporte y el sustento vital de sus habitantes. Entre estas actividades económicas, las relacionadas con el trabajo de la tierra tienen un papel preponderante, mientras la ganadería y la explotación de los recursos forestales y fluviales adquieren un importante papel complementario para

un buen número de familias en los siglos XIV y XV. Pero, además, en estas ciudades y villas también se desarrollan los sectores económicos mâs característicos del medio urbano: el artesanado y el comercio. En efecto, los gobiernos urbanos bajomedievales potencian estos sectores, desarrollándose de esta manera en el mundo urbano de La Rioja Alta una

\section{ABSTRACT}

All through the Middle Ages a series of different economical activities develop in the cities and towns of Rioja Alta. These activities are the support and sustenance of the citizens and, among them, agriculture has a special importance. Cattle raising and the exploitation of fluvial and forest resources become more and more significant as complementary activities for many families in the xIVth and xvth century. Besides, the most specific economical activities of the urban world, that is to say craftmanship and commerce, also develop in these cities and towns. In fact, the urban governments in Rioja Alta support these sectors and so, help to develop the craft production and commerce necesaries to provide the local markets with the food and products required by the population.

- Becario postdoctoral del Gobierno Vasco. Universidad de Valladolid (Depart. de Historia Medieval). E-mail: Fcog@arrakis.es 
producción artesanal y un sector

comercial capaces de abastecer al mercado local de aquellos productos

alimenticios $y$ artesanales

demandados por la sociedad.

\section{INTRODUCCIÓN}

La ciudad representa, sin ninguna duda, uno de los temas más interesantes para los investigadores que nos dedicamos al estudio de la sociedad de los siglos bajomedievales. En efecto, destacados representantes del Medievalismo europeo se han ocupado del mundo urbano, prestando atención a los diversos aspectos que caracterizan a la ciudad medieval; desde el urbanismo, a las instituciones, formas de gobierno, economía, vida cotidiana, etc. '.

Todos estos autores coinciden en señalar que la ciudad medieval presenta en general unas características bastante peculiares, con las que la identificamos en una primera aproximación: existencia de una muralla defensiva, un régimen jurídico privilegiado, unas funciones económicas diversificadas, heterogeneidad de grupos y organizaciones sociales, etc. No obstante, un análisis más detallado de los diferentes tipos de ciudades que caracterizaron al Occidente europeo medieval, nos lleva a la conclusión de la dificultad de homologar unos determinados criterios o requisitos de lo urbano para definir la ciudad medieval ${ }^{2}$. La sociedad que surge en el interior de los recintos amurallados de las ciudades y villas del Occidente europeo, presenta novedades, nuevas formas de organización, aunque ni mucho menos se encuentra aislada del entorno rural que la rodea, y que como ella se integra en un mismo marco de relaciones que caracterizan al sistema feudal ${ }^{3}$.

Como en el resto del Occidente europeo, también en el marco de la Corona de Castilla nos vamos a encontrar con una tipología muy variada

1 Giovanni Cherubini, Le città italiane dell'età di Dante, Pisa, 1991, Jacques Le Goff y VV.AA., La ville médiévale: des Carolingiens à la Renaissance, en Histoire de la France urbaine, tome 2, Tours, 1992, Rodney HiLTON, English and French towns in feudal society. A comparative study, Cambridge, 1992, Antonio Ivan PINI, Città, comuni e corporazioni nel medioevo italiano, Bologna, 1994, Jacques HeERS, La città nel Medioevo, Milano, 1995, José María MONSALVo ANTÓN, Las ciudades europeas del Medievo, Madrid, 1997.

José María Monsalvo ANTÓn, Las ciudades europeas..., o.c., pp. 9-17.

3 Angus MaCKay, “Ciudad y campo en la Europa Medieval», Studia Histórica, H. Medieval, vol. $n^{2} \|$ (1984), pp. 27-55. 
de núcleos urbanos, que ha sido puesta de manifiesto gracias al gran número de estudios monográficos que a lo largo de los últimos años se han ido realizando sobre ciudades y villas ${ }^{4}$. El trabajo que planteamos a continuación se centra en el mundo urbano de la Corona de Castilla, y concretamente se circunscribe a una región Nororiental: La Rioja Alta. Una región que representa un ejemplo de una evolución urbana similar en muchos aspectos a otras zonas del territorio castellano, pero que también tiene sus propias peculiaridades. Así lo hemos podido comprobar en las ocasiones en que hemos abordado diferentes aspectos de la vida urbana de las ciudades y villas de esta comarca; tales como el gobierno urbano, las finanzas concejiles o las relaciones de las ciudades con sus entornos rurales ${ }^{5}$. En esta ocasión vamos a centrar nuestra investigación en las actividades económicas que caracterizaron a los núcleos urbanos altorriojanos de la Baja Edad Media, concretamente nos ocuparemos de las actividades agropecuarias, del artesanado y del mercado local.

Nuestro análisis se va a centrar fundamentalmente en los núcleos urbanos de Logroño, Santo Domingo de la Calzada, Nájera y Haro, aunque haremos también algunas alusiones a Navarrete. Se trata de unas ciudades y villas de unas dimensiones bastante modestas, donde como ya veremos, el peso de las actividades económicas ligadas al sector primario va a tener un papel muy importante. No obstante, el desarrollo de cada uno de estos núcleos urbanos, nos va a ofrecer también diversos matices y unas personalidades variadas. En este sentido debemos tener presentes

4 Entre otros, Manuel Fernando Ladero Quesada, La ciudad de Zamora en la época de los Reyes Católicos. Economía y Gobierno, Zamora, 1991, José María MONSALvo ANTón, El sistema político concejil. El ejemplo del señorio medieval de Alba de Tormes y su concejo de villa y tierra, Salamanca, 1988, Juan Carlos MARTín CEA, El mundo rural castellano a fines de la Edad Media. El ejemplo de Paredes de Nava en el siglo xV, Valladolid, 1991, Yolanda Guerrero NavarRETE y José María SANCHEZ BENito, Cuenca en la Baja Edad Media: Un sistema de poder, Cuenca, 1994, José Ángel ACHON INSAUSTI, "A voz de concejo". Linaje y corporación urbana en la constitución de la Provincia de Gipuzkoa: los Báñez y Mondragón, siglos XII-xVI, San Sebastián, 1995, Maria Soledad Tena Garcia, La sociedad urbana en la Guipúzcoa costera medieval: San Sebastián, Renteria y Fuenterrabia (1200-1500), San Sebastián, 1997, Anselmo LOPEZ CARREIRA, A cidade de Ourense no século xv. Sociedade urbana na Galicia baixomedieval. Ourense, 1998. El interés por el tema urbano también se ha reflejado en diversos Congresos dedicados a esta temática, por ejemplo el II Congreso de Estudios Medievales "Concejos y ciudades en la Edad Media Hispánica”, celebrado en León en 1989, y cuyas Actas se publicaron en 1990, o más recientemente el $\checkmark$ Congreso de Estudios Medievales "Finanzas y fiscalidad municipal", celebrado en León en 1995, y cuyas Actas se han publicado en 1997.

5 FCo. Javier GoICOLEA JULIÁN, «Finanzas concejiles en la Castilla medieval: el ejemplo de La Rioja Alta (siglo xv-inicios del xvi)", revista Brocar, en prensa, y "Concejos urbanos en La Rioja Alta a fines del Medievo: aspectos institucionales y políticos", de próxima publicación en la revista Historia. Instituciones. Documentos $\left(n .^{\circ} 26,1999\right)$. 
las diferentes coyunturas que les afectarán, como su situación en la frontera con el reino de Navarra, su localización en el Camino de Santiago ${ }^{6}$, o la depresión bajomedieval y el cambio del eje comercial en favor de las rutas de Norte a Sur. Rutas que iban desde los puertos del Cantábrico a la Meseta castellana y viceversa ${ }^{\text {? }}$.

La documentación que vamos a utilizar para el presente estudio procede de las instituciones municipales y eclesiásticas de la comarca, que complementaremos con varios padrones fiscales que se han conservado en el Archivo de la Real Chancillería de Valladolid. Con todo ello pretendemos avanzar un poco más en nuestro objetivo final, que no es otro que el estudio de la articulación del poder en el mundo urbano de la comarca de La Rioja Alta. Para ello, el conocimiento de las bases económicas en que se sustentaba la sociedad urbana representa un punto de partida imprescindible ${ }^{8}$.

\section{EL PAPEL DECISIVO DE LAS ACTIVIDADES AGROPECUARIAS}

El volumen documental procedente de las diferentes instituciones asentadas en los núcleos urbanos altorriojanos en época bajomedieval, nos ofrece un gran número de datos sobre el papel destacado ejercido por las actividades económicas primarias en el conjunto de sus economías ${ }^{9}$. Un hecho que no es exclusivo de La Rioja Alta, pues la importancia funda-

6 José Ángel Garcia dE CORTAZAR, “El Camino de Santiago y la articulación del espacio en Castilla", Actas de la XX Semana de Estudios Medievales de Estella, Pamplona, 1994, pp. 157183, J. Ignacio RUIZ DE LA PENA, “La formación de la red urbana en el tramo riojano del Camino de Santiago y las colonizaciones francas (siglos XI-XIII)", Actas de la Reunión Científica "El Fuero de Logroño y su época", Logroño, 1996, pp. 211-230.

José Ramón DIAZ DE DURANA, «La recuperación del siglo xv en el Nordeste de la Corona de Castilla", Studia Histórica, H." Medieval, vol. $n^{2}$ VIII (1990), pp. 79-113.

8 El tema resulta a todas luces de gran interés y ha sido objeto de estudio en varias jornadas de la $X X X$ Settimana di Studi de Prato (Italia) "Poteri Economici e Poteri Politici. secc. XIII-XVIII" (1998).

9 Los casos mejor conocidos hasta el momento son el de la ciudad de Logroño (José Ramón Diaz de DuRana y Ernesto Garcia FERnández, Demografía y sociedad: la población de Logroño a mediados del siglo XV, Logroño, 1991, de estos mismos autores "Las actividades económicas en Logroño durante la Edad Media", texto original, agradezco a los citados profesores que me hayan proporcionado una copia de su investigación, Margarita CANTERA MONTENEGRO, "La hacienda concejil y la vida económica de Logroño en tiempos de los Reyes Católicos (1475-1495)", Anuario de Estudios Medievales, vol. ne 17 (1987), pp. 511-524, Fco. Javier GARCIA TURzA, "Logroño como centro articulador de su entorno rural", Historia de la ciudad de Logroño, Logroño, 1995, vol. $\mathrm{n}^{\mathrm{Q}}$ II (Edad Media), pp. 325-370), y el de la villa de Haro que he estudiado en mi Tesis Doctoral: La sociedad altorriojana a finales de la Edad Media: El ejemplo de la villa de Haro y sus aldeas (s. XV). 
mental de las actividades agrícolas y ganaderas, ha sido puesta de manifiesto también en otros núcleos urbanos de la Corona de Castilla ${ }^{10}$

A través de los documentos conservados podemos comprobar la existencia de numerosos pactos y acuerdos suscritos por las ciudades y villas, entre ellas mismas, o con aldeas e instituciones eclesiásticas por el aprovechamiento de términos agrícolas, pastizales, montes, aguas de riego, etc. ${ }^{11}$. Debemos tener en cuenta que los núcleos urbanos altorriojanos no consiguieron conformar alfoces extensos en la época foral, de ahí que a lo largo de los siglos XIII-XIV traten de expandirse hacia sus entornos rurales incorporando términos $y$ aldeas a sus jurisdicciones ${ }^{12}$. Este fenómeno expansivo vendrá motivado por diferentes intereses de carácter jurisdiccional, aumento de rentas para los concejos e influencia política, pero también tendrá que ver con intereses de carácter estrictamente económico.

De la misma forma, los órganos de gobierno de los núcleos urbanos tratan también de organizar y articular, mediante decretos y ordenanzas, las diferentes actividades agrícolas y ganaderas que se realizan dentro de sus jurisdicciones: vendimia, establecimiento de vedados para el ganado, plantación de majuelos y árboles frutales, regulación de jornales para los vendimiadores y segadores, etc. ${ }^{13}$. Algunas informaciones resultan especialmente significativas como fiel reflejo del importante peso que las actividades agrícolas tenían en estas ciudades y villas de la comarca altorriojana. Así, en 1490, los Reyes Católicos enviaban una provisión al alcaide de la fortaleza de Logroño, en la que se le ordenaba abrir la puerta del puente de la ciudad a una hora temprana y cerrarla bien entrada la tarde, pues si no se obstaculizaba a los campesinos el desempeño de sus actividades agrícolas ${ }^{14}$. En Haro, el concejo de la villa regulaba en 1476

10 José María SAnchez Benito, Las tierras de Cuenca y Huete en el siglo xIV, Cuenca, 1994 , Carmen Fernandez-DAZA AlVEAR, La ciudad de Trujillo y su tierra en la Baja Edad Media, Madrid, 1991, Juan Carlos MARTín CEA titula su estudio sobre la villa palentina de Paredes de Nava con el significativo título de El mundo rural castellano a fines de la Edad Media..., o.c., Anselmo LóPEZ Carreira, A cidade de Ourense no século XV..., o.c.

11 Así se puede comprobar a partir de la documentación procedente del Archivo Municipal de Santo Domingo de la Calzada (Ciriaco LOPEZ DE SILANES y Eliseo SAinz RIPA, Colección Diplomática Calceatense. Archivo Municipal (1207-1498), Logroño, 1989).

12 Pascual Martínez Sopena, "Logroño y las villas riojanas entre los siglos XII y XIV", Historia de la ciudad de Logroño..., o.c., pp. 279-322).

13 «En rason de la obrerisa que se aya de dar a podar a XII maravedis e a cabar a XIII maravedis e en la mannana una taça de vino con un poco de pan e en la noche en viniendo otra taça de vino, e qualquier que trasçediese de los dichos preçios e otra cosa alguna diere de mas de lo sobredicho incurra en la pena de sesenta maravedis" (A.M.H.: LA. 1476, sesión de concejo amplio del 13 de marzo).

14 A.M.L.: $7 / 7$. 
los precios de las «herramientas perteneçientes para la labrança de pan e vino" que debian de realizar los herreros ${ }^{15}$.

Si nos atenemos a la información que nos proporcionan los testamentos, también podemos comprobar que los bienes raíces y muebles que cedian los testadores se correspondían con unas haciendas típicamente rurales. De esta forma, junto a las tierras de cereal, viñedos, huertas, linares, etc. que se inscriben en los testamentos, también podemos comprobar que los testadores eran propietarios según su posición económica de molinos, bodegas, corrales, trujales, animales de tiro y labranza, además de diversos útiles agrícolas como azadas, legones, comportas, cinchas, calderas, cedazos, etc. ${ }^{16}$.

A partir de los datos que nos proporciona la documentación concejil contable, también podemos llegar a algunas conclusiones referentes al importante peso del sector agrícola. De esta forma, si bien la evolución de los ingresos concejiles en especie (trigo y cebada) no es muy ilustrativa desde el punto de vista que sólo refleja las heredades pertenecientes a los propios del concejo, sí lo es por el hecho de que los arrendatarios de heredades concejiles pagaban sus rentas también en cereal. Lo mismo sucedía con los arrendamientos de los molinos concejiles, cuyas rentas debían de ser satisfechas en fanegas de trigo. En efecto, así lo hemos podido comprobar en los núcleos urbanos de Nájera y Haro ${ }^{17}$.

El cereal constituía el cultivo más importante dentro de los términos rurales que controlaban los núcleos urbanos de La Rioja Alta ${ }^{18}$. La explotación cerealística estaba generalizada, pues a un clima y unos suelos apro-

15 A.M.H.: LA. 1476, sesión de concejo amplio del 14 de marzo.

16 Para Logroño y Haro me remito a los trabajos citados en la nota nueve, para Santo Domingo de la Calzada pueden verse algunos testamentos en (Ciriaco LóPEZ DE SILANES y Eliseo Sánz RiPa, Cclección Diplomática Calceatense. Archivo Catedral (1451-1499) y Archivo del Hospital (1431-1497), Logroño, 1992, documentos del Archivo del Hospital, docs. $n^{\circ} 20$ y $n^{\circ} 29$.

17 Fco. Javier Golcoléa JuLián, "Las finanzas concejiles y la fiscalidad de Nájera en la segunda mitad del siglo xv. El ejercicio del bolsero Martín Romero (1476-1477)", Espacio, Tiempo y Forma, H. ${ }^{a}$ Medieval, vol. $n^{2} 9$ (1996), pp. 119-135, “Finanzas concejiles en la Castilla medieval: ...", o.c., y mi Tesis Doctoral: La sociedad altorriojana..., o.c., pp. 530-657.

18 La importancia del cultivo de cereal ya se constata en La Rioja Alta en los siglos altomedievales (José Ángel GARCIA DE CORTÁZAR, El dominio del monasterio de San Millán de la Cogolla (siglos $x$ al $x$ III). Introducción a la historia rural de la Castilla altomedieval, Salamanca, 1969, “Crecimiento demográfico y ordenación del espacio en La Rioja Alta en el siglo Xl", Anuario de Estudios Medievales, $\mathrm{n}^{2} 15$ (1985), pp. 63-83, María del Carmen FERnÁndez DE LA PRADILLA MAYORAL, "El cultivo de cereales en la Rioja durante el siglo Xl", Berceo, $n^{Q} 118-119$ (1990), pp. 193-206, Diana SALAS DUQUE, "Terminología de la producción y organización de los espacios de cereal en la Rioja en los siglos x a XII", Actas del "Coloquio sobre Historia de La Rioja, vol. $n^{2}$ I (1985), pp. 289-302. 


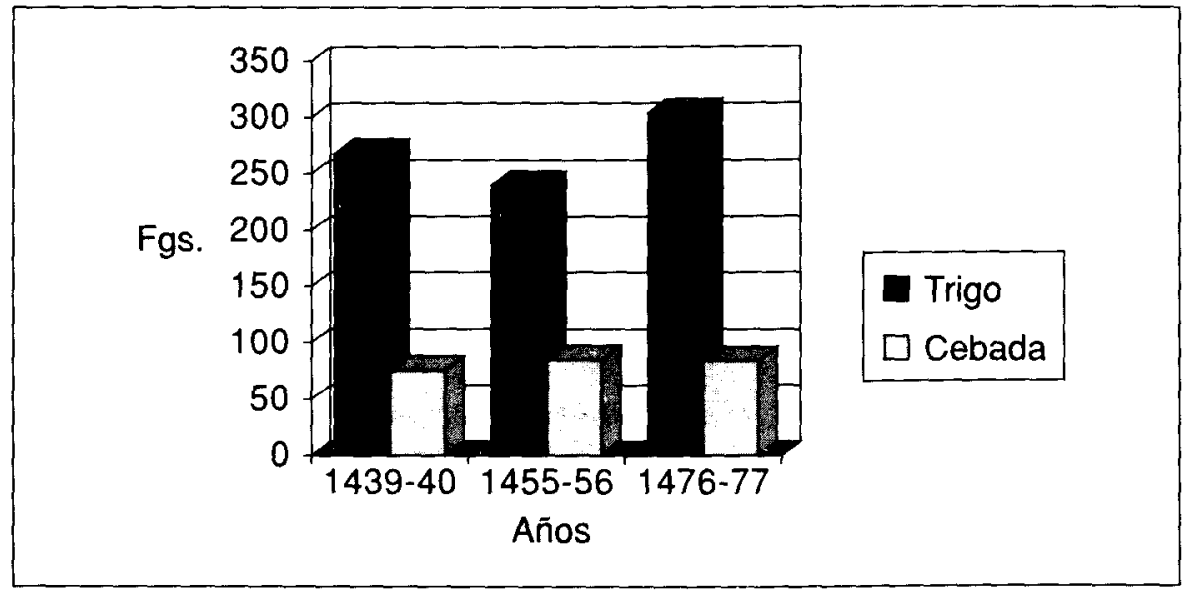

Fuente: A.M.N.: LC. 1439-40, 1455-56 y 1476-77.

Gráfico I. Grano recaudado por la Hacienda Concejil de Nájera (en fanegas).

piados se unía el hecho de que el cereal podía conservarse satisfactoriamente durante mucho tiempo sin perder sus propiedades alimenticias. El trigo era el cereal panificable por excelencia y tenía un papel fundamental en la alimentación humana, mientras que la cebada se destinaba principalmente al consumo del ganado ${ }^{19}$. Algunos datos cualitativos que nos informan sobre la importancia del cultivo de trigo, son las constantes prohibiciones que hace el concejo de Haro a lo largo del siglo XV de espigar y coger alfalfa silvestre, la denominada «mielga», en los campos de trigo ${ }^{20}$, - las prohibiciones para acudir a segar fuera de la villa: "que ningund vesino de la villa non baya a segar fuera por quanto es cosa que cunple mucho a serviçio del nuestro sennor don Bernaldino e al bien e provecho de la dicha villa so pena que el que se fuere que sepa que le echaran de

19 Fco. Javier García TuRzA, «Logroño como centro articulador..., o.c., pp. 325-370 y mi Tesis Doctoral: La sociedad altorriojana..., o.c., pp. 238-298. El predominio del cultivo del cereal y dentro de él del trigo también ha sido puesto de manifiesto por otros autores para la vecina comarca de Rioja Alavesa (Ernesto Garcia FERnánDEZ, "Economia y sociedad de la comunidad de Villa y Tierra de Laguardia durante la Baja Edad Media", Actas del Congreso de Estudios Históricos: La formación de Alava, comunicaciones, vol. $n^{2}$ I, Vitoria, 1985, pp. 387-403, José Ramón DíAZ DE DURANA, “La recuperación el siglo Xv..., o.c., pp. 79-113, Luis Maria BILBAO BıLBAO y Emiliano FEANANDEZ DE PINEOO, “La producción agrícola en el País Vasco peninsular 1537-1850. Tendencia general y contrastes comarcales. Una aproximación", Cuadernos de sección: Historia-Geografía de la Sociedad de Estudios Vascos-Eusko Ikaskuntza, vol. $n^{2} 2$ (1984), pp. 83-199).

20 A.M.H.: LA. 1470, sesión de concejo amplio del 4 de julio. 
la villa su muger e fijos" ${ }^{21}$. La primacía de este cereal también queda puesta de manifiesto a través de los datos que nos proporcionan los importes de la renta de la primicia de la iglesia de Santo Tomás de Haro, el pago del diezmo según las averiguaciones de 1537-1541, así como los apeos de heredades concejiles que se han conservado ${ }^{22}$.

Junto al cereal, el cultivo del viñedo fue el más importante en la Edad Media. En La Rioja Alta, este cultivo, documentado ya en los siglos altomedievales ${ }^{23}$, irá ganando espacio a lo largo de los siglos bajomedievales en detrimento de las tierras de cereal. En Santo Domingo de la Calzada, ya desde finales del siglo XIII tenemos constancia de que el cabildo calceatense arrendaba algunas de sus heredades a condición de que el arrendatario "plantasse viña en ella cadaño cossa çierta ffasta que cada ffuese plantada e ssi por aventura lo non cunpliesse assi que me podiessedes tyrar la pieça e lo que oviese plantado en ella" ${ }^{24}$. En Logroño, Fco. Javier García Turza, ha distinguido dos momentos concretos del avance de la viña a costa del cereal. Un primer momento entre 1339 y 1379 , en plena crisis socio-económica, y un segundo momento entre 1425 y 1470 . Según este autor, en el primer período, los monjes del monasterio de San Martín de Albelda, en un afán por recuperar el valor de sus antiguas rentas, habrian decidido arrendar sus parcelas, yermas en su totalidad, con la condición que se plantasen de viña. En el segundo momento el monasterio de Valcuerna y el cabildo de La Redonda se servirán de los censos como medio de explotar su hacienda, en parte también baldia ${ }^{25}$. La propia aparición reiterada del término "majuelo", indicador de una viña nueva plantada sobre tierra ya roturada, incide también en la expansión del viñedo ${ }^{26}$. En efecto, la producción de vino en los núcleos urbanos altorrionajos, al igual que en sus vecinos de La Rioja Alavesa, fue en aumento a lo largo

${ }^{21}$ A.M.H.: LA. 1478, sesión de concejo restringido del 10 de julio.

22 Me remito a mi Tesis Doctoral: La sociedad altorriojana..., o.c., pp. 238-298.

23 José Ángel Garcia de Cortazar, El dominio del monasterio de San Millán..., o.c., María del Carmen Fernandez de la Pradilla Mayoral, "El viñedo en la Rioja durante el siglo XI", Berceo, $n^{2} 122$ (1992), pp. 61-77.

24 Ciriaco LóPEZ DE SILANES y Eliseo SÁInz RIPA, Colección Diplomática Calceatense. Archivo Catedral (Años 1125-1397), Logroño, 1985, doc. $n^{2} 67$.

25 Fco. Javier Garcia TuRzA, «Logroño como centro articulador..., o.c., p. 348.

26 «Mandaron que los sobrejurados e montaneros puedan motagar a los carneros e ovejas $e$ corderos e corderas e puercos que andubieren en danno de pan e vino e majuelos nuevos" (A.M.H.: LA. 1454, sesión de concejo amplio del 29 de junio) "por quanto paresçe que algunos vesinos de esta villa tienen entrado en los exidos del conçeio de Çaco e Dondon e en otras partes e tienen plantados majuelos" (A.M.H.: LA. 1472, sesión de concejo amplio del 29 de enero) "por çiertos maiuelos que eran plantados en el termino que dizen de Rroturas fasta carrera Gallinero por algunos vezinos de la dicha çibdat" (Ciriaco LOPEZ DE SILANES y Eliseo Sainz RIPA, Colección Diplomática Calceatense. Archivo Municipal..., o.c., doc. $n^{2} 41$, p. 113). 


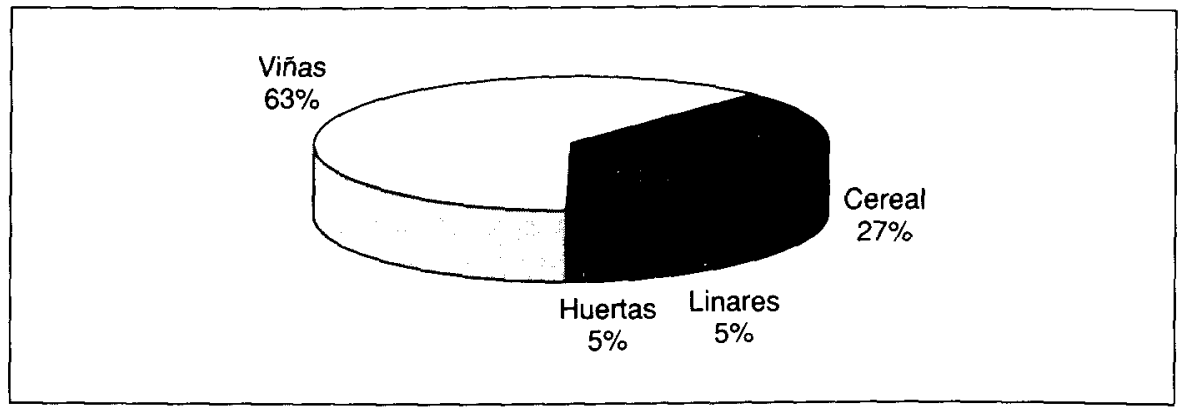

Fuente: A.H.N.: Clero, leg. 2.856, apeo efectuado en 1507.

Gráfico II. Heredades del Convento de San Agustín en el término jurisdiccional de Haro a fines de la Edad Media.

de la segunda mitad del siglo XV, acelerándose en las primeras décadas del siglo XVI ${ }^{27}$.

Después de los cultivos principales, cereales y vid, el resto del terrazgo cultivable estaba conformado por linares, cañamales y huertas, cultivos que se concentraban fundamentalmente en los "pagos" más fértiles cercanos a los núcleos urbanos ${ }^{28}$. Incluso, en el caso de las huertas, también dentro de los propios recintos amurallados, teniendo como límites calles, hospitales o la misma muralla ${ }^{29}$. En las huertas se cultivaban verduras como ajos, rábanos, perejil, cebolletas, berzas, nabos, puerros y lechugas, así como legumbres ${ }^{30}$, y de acuerdo con los ingresos de frutos de la primicia de la iglesia de Santo Tomás de Haro, en el término de esta villa debian sobresalir las producciones de habas y ajos ${ }^{31}$. El cultivo de horta-

${ }^{27}$ Según José Ramón DiAz dE DuRANA, el resultado más destacable de la recuperación demográfica y económica del siglo xv en La Rioja Alavesa y en La Rioja Alta, será la consolidación de su especialización vitivinícola. Una especialización destinada a abastecer a las provincias costeras vascas a través de la ciudad de Vitoria "La recuperación del siglo xv..., o.c., pp. 97 y 98.

${ }_{28}$ Los pagos eran los distritos rurales donde se concentraban las tierras de cultivo de los términos de las ciudades y villas (FCo. Javier GARcíA TURZA, "Logroño como centro articulador..., 0.c., p. 344, también referencias a pagos en Nájera, A.M.N.: LC. 1439-40, cuenta de ingresos en dinero, en Haro La sociedad altorriojana..., o.C., p. 257, y en otras comarcas de la Corona de Castilla, Juan Carlos MARTíN CEA, El mundo rural castellano..., o.c., p. 92).

29 Fco. Javier GAacía TURzA, “Logroño como centro articulador..., o.c., p. 345. También constatamos la existencia de huertos dentro del recinto amurallado de Santo Domingo de la Calzada, concretamente en el Barrio Nuevo (Ciriaco Lópz de SILANES y Eliseo SAinz RIPA, Colección Diplomática Calceatense. Archivo Catedral (Años 1125-1397).., o.c., doc. $n^{2} 95$ y Colección Diplomática Calceatense. Archivo Catedral (1400-1450), Logroño, 1991, doc. $n^{2} 169$ ).

30 Me remito a mi Tesis Doctoral: La sociedad altorriojana..., o.c., p. 250.

31 lbidem., p. 248. 
lizas tuvo una destacable importancia, y así se desprende de la localización de un buen número de huertos en los términos de Logroño o Haro ${ }^{32}$, e igualmente son frecuentes las menciones documentales a hortelanos y fruteros ${ }^{33}$. En Haro, las ordenanzas de 1453 limitaban a una fanega de sembradura las heredades dedicadas a huerta que los vecinos de la villa podían tener en los pagos de regadío "porque los dichos nuestros vezinos ayan lugar donde senbrar e coger cunplimiento de pan e mantenimiento e provision de esta villa" ${ }^{34}$. En los linares y cañamales se cultivaba el lino y el cáñamo, fibras vegetales que utilizaban los artesanos textiles en la realización de telas de lienzo, así como en la confección de cuerdas, cinchas o alforjas. En estos linares y cañamales, pero sobre todo en las huertas, se concentraban también un buen número de árboles frutales como manzanos, perales, ciruelos, nogales, cerezos, guindos, almendros, castaños y olivos ${ }^{35}$.

El aprovechamiento de los cursos fluviales para el riego de las tierras de cultivo tenía una importancia vital, que queda claramente puesta de manifiesto a través del gran número de pleitos mantenidos por las ciudades y villas riojanas por el control de los recursos hídricos ${ }^{36}$. El regadío era conocido en La Rioja desde la época romana, y con la invasión musulmana al sistema romano de pozos debió de sumarse el sistema de riego por rehizo y acequias ${ }^{37}$. El aprovechamiento del agua para el regadío está documentado en La Rioja Alta desde el siglo $x$, pero es sobre todo en el siglo $x \vee$ cuando la abundancia de pleitos por el control del agua nos pone de manifiesto su importancia. En efecto, podemos constatar que en el término de Logroño, los pagos de viñedo estaban comunicados a través de unas redes de regaderas con el fin de mejorar la producción vitícola y la calidad del vino ${ }^{38}$. También en Haro, a través de la abundante documentación concejil que se ha conservado, sabemos que el regadío se

32 Ibidem., pp. 250 y 251 y Fco. Javier GARCiA TuRzA, «Logroño como centro articulador..., o.c., p. 346 .

33 En un padrón fiscal de Santo Domingo de la Calzada de 1503 aparecen inscritos dos fruteros en el barrio de la Cal del Medio (A.R.CH.V.: Sala de Hijosdalgo, leg. 20-1).

$34 \quad$ A.M.H.: L.B.P.V.H., fols. $65 \mathrm{v}^{9}-67 \mathrm{v}^{\mathrm{Q}}$.

3s Me remito a mi Tesis Doctoral: La sociedad altorriojana..., o.c., p. 251 y Fco. Javier GaRciA TURzA, “Logroño como centro articulador..., o.c., p. 346.

36 Julio Miguel LÓPEZ ARqOYO, Aspectos juridicos del regadío tradicional riojano, Logrofío, 1994, Fco. Javier GaRcla TURzA, Logroño como centro articulador..., o.c., pp. 353-354, Ciriaco LOPEZ dE SIlanes y Eliseo SáInz RIPA, Colección Diplomática Calceatense. Archivo Municipal..., o.c., docs. $n^{2} 49$ y $n^{2} 51$.

37 Julio Miguel LOPEZ ARROYo, "Aproximación a la Historia del regadio riojano", Berceo, $n^{\circ} 112-113$ (1987), pp. 101-123.

38 Ernesto García Fernández y José Ramón Díaz de DuRAna, “Actividades económicas en Logroño..., o.c., p. 3. 
extendía por un buen número de "pagos" del término de esta villa, empleándose como en otras zonas del norte de la Corona de Castilla el sistema de la gravedad, mediante la utilización de "presas", "canales", «estancas", "costaneras" y "regaderas" ${ }^{39}$. El riego era regulado en cada uno de los "pagos" por varias personas nombradas por el concejo, que se encargaban de establecer además los días de la semana que los vecinos podían regar en cada uno de los "pagos". Todo ello con la finalidad de lograr una distribución proporcional de las aguas de riego entre los regantes ${ }^{40}$. A través de los Libros de actas del concejo de Santo Domingo de la Calzada, también podemos comprobar cómo las autoridades municipales de esta ciudad se preocupaban por el riego de las heredades, especialmente el de aquellas dedicadas al cultivo del lino ${ }^{41}$.

Estrechamente relacionados con la energía hidráulica se encuentran los molinos, imprescindibles para moler el cereal producido por los campesinos. Desde los inicios de la repoblación de la comarca altorriojana, tenemos noticias sobre la construcción de molinos a lo largo de los ríos que surcan este territorio ${ }^{42}$. Tal y como afirma José Ángel García de Cortázar, en principio su única finalidad será la molturación de los granos, siendo posteriormente utilizados también en otras actividades como el riego ${ }^{43}$. A partir de la Plena Edad Media y a lo largo de los siglos bajomedievales, las menciones a molinos en los términos de los núcleos urbanos altorriojanos aumentan considerablemente ${ }^{44}$, e incluso se localizan en el interior de los recintos urbanos, como ocurria en Nájera ${ }^{45}$. Sus propietarios son los concejos, cabildos y los señoríos laicos y eclesiásticos, pero también vecinos particulares con un considerable nivel de renta,

39 Este sistema también era utilizado en la comarca de Burgos, tal y como lo ha puesto de manifiesto Hilario CASADO ALONSO, Señores, mercaderes y campesinos. La comarca de Burgos a fines de la Edad Media, Valladolid, 1987, p. 205. El riego por regaderas también se practicaba en el término rural de la cercana villa de Laguardia (Ernesto GARcia FERNÁNDEZ, "Economia y sociedad..., o.c., p. 387).

40 Me remito a mi Tesis Doctoral: La sociedad altorriojana..., o.c., pp. 273-276.

41 "Mandaron que en lo de los riegos del lino agan regar a sus duennos las heredades que mas nesçesidad tyenen" (A.M.S. ${ }^{2}$ D. ${ }^{9}$ C.: LA. 1512, sesión del 26 de junio).

42 José Ángel GARCIA DE CORTÁZAR, «El equipamiento molinar en la Rioja Alta en los siglos $x$ a XIII», Estudios en Homenaje a Fray Justo Pérez de Urbel, Silos, 1976, vol. n² I, pp. 387-405.

43 José Ángel Garcia de CoRtázAR, El dominio del monasterio de San Millán..., o.c., pp. 250251.

44 En Santo Domingo de la Calzada constatamos desde el año 1125 los términos de Los Molinos, Molino de los Aniversarios, Molino del Hospital, Molino de Bujedo y Molino de Sanch Andreo (Ciriaco LOPEZ dE SILANES y Eliseo SÁInz RIPA, Colección Diplomática Calceatense. Archivo Catedral (Años 1125-1397)..., o.c., p. 300).

45 Fco. Javier García TuRzA, "Morfología de la ciudad de Nájera en la Edad Media", Actas de la III Semana de Estudios Medievales de Nájera, Logroño, 1993, pp. 63-88. 
pues la construcción y mantenimiento de los molinos resultaba bastante costosa ${ }^{46}$.

A partir de la documentación concejil de Haro, hemos podido comprobar que los molinos situados en el término de esta villa, utilizaban la misma infraestructura del regadío. En efecto, el agua de los cauces fluviales más importantes, Ebro y Tirón, era desviada por medio de «presas" hacia el molino a través de "calses" y "canales" artificiales, precipitándose el agua por los "canales" de los molinos hacia las ruedas, cuyo movimiento hacía girar los "rodetes", que a su vez hacían girar las «muelas" encargadas de molturar el grano ${ }^{47}$. Igualmente abundantes son las menciones a molineros, $y$ en efecto en Logroño aparecen dos molineros inscritos en un padrón fiscal de 1454, en Navarrete se inscriben igualmente dos en 1483, y en Santo Domingo de la Calzada contabilizamos un total de diez molineros en 1503, nueve de los cuales se inscriben en el barrio de la Puebla ${ }^{48}$. En Nájera, dos molineros de la ciudad arrendaron los molinos del concejo en el período 1476-77 ${ }^{49}$.

Además de las tierras de cultivo, también se extendian por los términos rurales de las ciudades y villas otros terrenos ocupados por eras, ejidos, dehesas, montes y sotos. Estos lugares eran objeto de explotación por parte de los vecinos, pero por ser en su mayoría bienes comunes, el concejo se encargaba de regular el aprovechamiento de los mis-

46 Fco. Javier García TuRzA, “Logroño como centro articulador..., o.c., p. 354-355, el concejo de Nájera era propietario de varios molinos que arrendaba todos los años (Fco. Javier GoicolEA JULı̇̇N, "Las finanzas concejiles y la fiscalidad de Nájera..., o.c., pp. 119-135), en el término de Haro eran propietarios de molinos el concejo, el cabildo y la iglesia de Santo Tomás, así como varios miembros de la élite social de la villa (me remito a mi Tesis Doctoral: La sociedad altorriojana..., o.c., pp. 267-273). En 1462 se repartió un "pecho" entre los vecinos de la villa de Haro para sufragar los gastos de la construcción de un molino, recaudándose 10.502 maravedís (A.M.H.: LC. 1462, cuenta de gastos en dinero). El cabildo calceatense también era propietario de molinos; de esta forma sabemos que en 1287 compró un molino cercano a la ciudad al abad del monasterio de Bujedo, y en 1322 al concejo y vecinos del lugar de Ayuela (Ciriaco LOPEZ DE SILANES y Eliseo SÁINZ RIPA, Colección Diplomática Calceatense. Archivo Catedral (Años 1125-1397)..., o.c., docs. $n^{2} 52$ y $n^{2} 77$ ). El agua y los molinos fueron fuente de disputas entre los concejos y los señores de la comarca, y en efecto en 1494 el concejo de la ciudad de Santo Domingo de la Calzada, se quejaba porque el señor Pedro Manrique habia tomado para sus molinos el agua del cauce que pasaba por el término de Santurde. Agua que era indispensable para el abastecimiento de la ciudad, que por esta razón se quedaba casi sin agua a partir del dia de san Juan (A.G.S. R.G.S., fol. 477 (27-X-1494).

47 Me remito a mi Tesis Doctoral: La sociedad altorriojana..., o.c., pp. 271-273.

48 José Ramón Diaz de DuRANa y Ernesto Garcia Fernández, Demografía y sociedad..., o.c., p. 28 y A.R.CH.V.: Sala de hijosdalgo, legs. $453-4$ y $20-1$

49 "Resçibi de Martyn de Soria e de Juan de Açofra molineros de los molinos del conçeio dosientas e veynte fanegas de trigo, arrendaronse por quatro annos e es este el primero" (A.M.N.: LC. 1476-77, cuenta de ingresos en grano). 


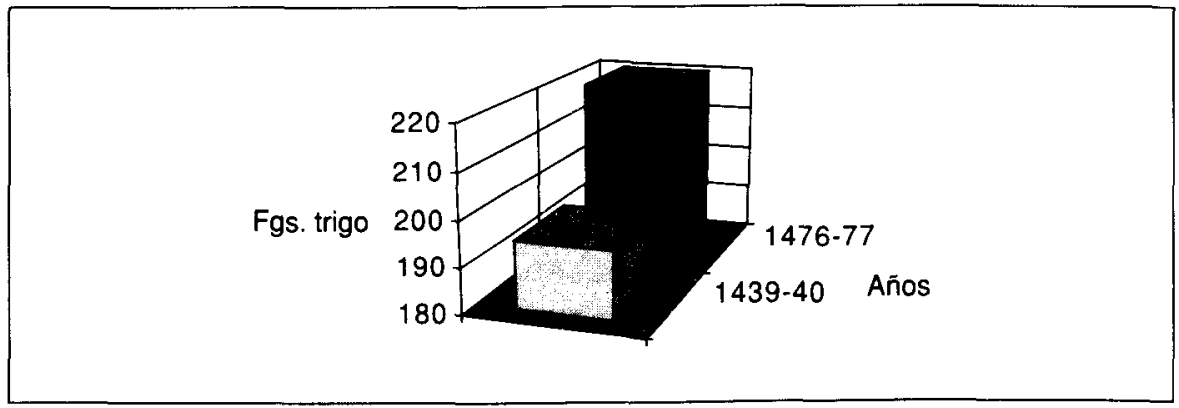

Fuente: A.H.N.: LC. 1439-40 y 1476-77

Grafico III. Ingresos del Concejo de Nájera procedentes de la renta de los molinos (en fanegas de trigo).

mos ${ }^{50}$. De esta forma, reglamentaba el uso que se podía hacer del ejido, poniendo freno a las constantes tentativas de los vecinos, que trataban de ampliar sus heredades a costa del mismo, mediante la realización de roturas clandestinas ${ }^{51}$. De las dehesas, montes y sotos los vecinos se abastecían de leña para sus hogares y de madera, indispensable para la construcción o para la realización de aperos de labranza ${ }^{52}$. En los sotos también recogían los mimbres, que eran muy apreciados para la realización de todo tipo de recipientes de cestería ${ }^{53}$. El concejo reglamentaba igualmente el aprovechamiento de los montes y bosques, más aún por el

50 José Luis MARTín, "Evolución de los bienes comunales en el siglo XV", Studia Histórica, Historia Medieval, vol. $n^{\otimes}$ VIII (1990), pp. 7-47. Gestión que también reportaba a las haciendas concejiles algunos ingresos (Miguel Ángel LADERO QUESADA, "Las haciendas concejiles en la Corona de Castilla (Una visión de conjunto)", Actas del V Congreso de Estudios Medievales: Finanzas y fiscalidad municipal, León, 1997, pp. 9-71, especialmente pp. 20-24).

51 "Que ninguno non entrase en los exidos conçejiles e asi mesmo los que lo abian entrado lo dexasen (A.M.H.: LA. 1471, sesión de concejo amplio del 11 de noviembre).

52 "El conçeio mando que todas las iugadas fagan ir e bayan por la madera al puerto" (A.M.H.: LA. 1464, sesión de concejo amplio del 23 de julio). Los compromisos y concordias establecidos entre los concejos vecinos por el aprovechamiento de montes, son un buen ejemplo de la importacia que la explotación de éstos tenía para las ciudades y villas altorriojanas (Ciriaco López de Silanes y Eliseo Sainz RiPa, Colección Diplomática Calceatense. Archivo Municipal..., o.c., docs. $n^{9} 49, n^{9} 51$ y $n^{2} 54$, A.M.L.: 2/21, 5/5). Lo mismo ocurría en otras comarcas de la Corona de Castilla (José María SÁnCHEZ Benito, Las tierras de Cuenca y Huete..., o.c., pp. 173-175 y Carmen Fernánoez-Daza Alvear, La ciudad de Trujillo y su tierra en la Baja Edad Media, Madrid, 1991, pp. 388-391).

53 QQue en los dichos sotos e pastos non entren en ellos bestias ningunas folgadas...e que ninguno non corte minbres de los dichos sotos so pena de dies maravedis por cada gabilla" (A.M.H.: LA. 1466, sesión de concejo restringido del 9 de abril). 
hecho de que los términos rurales de las ciudades y villas altorriojanas carecian de abundantes masas boscosas ${ }^{54}$.

Estos terrenos incultos también se utilizaban para la alimentación de la cabaña ganadera de los pobladores de las ciudades y villas ${ }^{55}$. Los núcleos urbanos poseían en sus términos rurales terrenos adehesados, reservados a los miembros de la comunidad, pero además disponían de otra área de pasto conformada por el ejido y los montes de explotación comunal. También servían de pastizales los barbechos, las tierras incultas, los campos en general en el período que iba de la recolección a la siembra, así como las tierras dedicadas expresamente a pastos cultivados ${ }^{56}$. Incluso, Fco. Javier García Turza ha podido constatar que en Logroño también las viñas eran utilizadas como pastizales, llevando a cabo las ovejas el despampanado de las viñas y fertilizando los suelos ${ }^{57}$. Los concejos urbanos ponían una gran diligencia en la reglamentación del espacio pastoril, y así mismo en la vigilancia del cumplimiento de las ordenanzas redactadas a este respecto. En efecto, en Haro hemos podido comprobar cómo a lo largo del siglo $\mathrm{xv}$, el concejo elegía todos los años a los guardas de la cabaña ganadera de la villa (guardas de mulas hembras, machos cojudos y castrados, bueyes, vacas, cabras y puercos), y a través de diversos oficiales (sobrejurados, montaneros y guardas de los pagos) penalizaba a los propietarios de ganado que incumplían las ordenanzas ${ }^{58}$.

54 El concejo de Haro tuvo que recurrir varias veces a lo largo del siglo $x v$ al arrendamiento de algún monte a la villa de Peñacerrada (A.M.H.: LA. 1482, sesión de concejo amplio del 5 de enero). En Logroño tenemos noticias sobre repoblaciones de montes a inicios del siglo XVI. El 19 de junio de 1518 el monarca Carlos I ordenaba al corregidor de la ciudad la plantación de álamos, sauces, pinos y otras especies en los lugares del término fijados para ello, y el 11 de febrero de 1519 el avuntamiento de Logroño acordaba la "plantación de montes" en su jurisdicción (A.M.L.: $16 / 6$ y $16 / 9)$.

55 En algunas concordias entre los concejos por el aprovechamiento de pastos comunales, se estipulan minuciosamente las penas que se debian imponer a las diferentes especies pecuarias "Otrosy fallamos que en cuanto toca a los ganados yeguas e rroçines de los dichos conçeios e cada uno de ellos çerriles que andan sin guarda e pastor que estos tales ganados sy paçieren $e$ dormieren de noche en los terminos propios de los conçeios e cada uno dellos que estos tales ayan de pena de cada un ganado de noche un maravedi..." (Ciriaco LóPEZ DE SILANES y Eliseo Sainz RIPA, Colección Diplomática Calceatense. Archivo Municipal..., o.c., doc. $\mathrm{n}^{0}$ 50). En los padrones fiscales que se han conservado aparecen inscritos pastores, dos en Logroño en 1454 , uno en Navarrete en 1483 y cuatro en Santo Domingo de la Calzada en 1503.

56 Fco. Javier Garcia TuRzA, «Logroño como centro articulador..., o.c., pp. 355-358 y mi Tesis Doctoral: La sociedad altorriojana..., o.c., pp. 294-304.

57 Fco. Javier Garcí TuRzA, Logroño como centro articulador..., o.c., p. 357.

58 Me remito a mi Tesis Doctoral: La sociedad altorriojana..., o.c., pp. 298-304. Un ejemplo similar de reglamentación pastoril se observa en la villa palentina de Paredes de Nava (Juan Carlos MARTIN CEA, El mundo rural castellano..., o.c., pp. 120-125. 
En las labores agrícolas la fuerza de trabajo animal era fundamental, de ahí el importante papel jugado por las denominadas en la documentación "bestias de labranza", que comprendían a los bueyes, mulas, machos y rocines. Ganado de labranza cuya alimentación en los pastizales del término rural era evidentemente prioritaria en relación a los denominados «ganados folgados" 59 . Éstos comprendían desde los caballos, yeguas y mulas de silla, hasta burros y vacas, pasando por la más numerosa cabaña ovina y caprina. En efecto, en Haro, el concejo de la villa prohibió en 1465 a cada vecino meter más de cincuenta ovejas en los términos delimitados a tal efecto, y en 1491 reglamentó en número de cuatro las cabras que los cristianos y moros podían traer a la villa ${ }^{60}$. En Haro hemos podido comprobar cómo a lo largo del siglo $x \vee$ y a medida que iba en aumento la presión sobre la tierra, el concejo tuvo que tomar la determinación de limitar la cabaña ganadera ovina de la villa para primar la agricultura, puesto que en esta actividad se sustentaba la economía de la mayor parte de los vecinos ${ }^{61}$.

El ganado porcino también jugó un papel muy importante en la economía familiar, puesto que el cerdo podía ser alimentado con todo tipo de desperdicios, y cuando llegaba la matanza, prácticamente todo él se aprovechaba. Esto hizo que fuera necesario sacar a los cerdos a apacentar en "manadas", bajo el cuidado de un pastor o "porquerizo" ${ }^{62}$. La cabaña ganadera se completaba con las aves de corral, gallinas, capones, pollos y ansarones, que debían ser bastante corrientes en los corrales de los vecinos, ya que en las relaciones de presentes y "yantares" concedidos por los concejos a diferentes dignatarios, y que se asientan en los Libros de cuentas de Nájera y Haro, aparecen reiteradamente ${ }^{63}$.

59 "Por quanto algunas personas trayan en los prados de la dicha villa çiertas vacas e los quales dichos pastos heran mas nesçesarios para los ganados de labrança que non para otros ganados folgados, que ordenaban que ningund vesino de la villa non sea osado de traer bacas en los dichos prados nin ningunos ganados folgados so pena de seisçientos maravedis" (A.M.H.: LA 1461, sesión de concejo restringido del 26 de noviembre).

60 Me remito a mi Tesis Doctoral: La sociedad altorriojana..., o.c., pp. 294-304.

61 lbidem. Una situación similar se observa en la villa palentina de Paredes de Nava (Juan Carlos Martín CEa, El mundo rural castellano..., o.c., pp. 120-125.

62 «...mandamos que ningunos pastores de los puercos del dia de San Miguel fasta el dia de Sant Andres en tienpo de fruy que non puedan entrar en los dichos montes con los dichos puercos e que si entraren que paguen por cada manada de diez puercos arriba a treynta maravedis e que si algund ataio de los dichos puercos se apartare por rradios que entrare en qualquier de los dichos montes en pos de la dicha grana que por aquello que non les sea levada pena con iuramento que agan los dichos pastores que se le ataiaron entiendase de ataio que sea de fasta treynta puercos..." (Ciriaco López de SILANES y Eliseo SÁINZ RIPA, Colección Diplomática Calceatense. Archivo Municipal..., o.c., doc. $n^{2} 57$, p. 213).

63 Por ejemplo en los alimentos que se concedieron a la Reina, a la Princesa y a su séquito en Nájera en 1440 (A.M.N.: LC. 1439-40, cuenta de gastos en dinero). 
Finalmente, como actividades complementarias de la agricultura y de la ganadería, la caza y la pesca también jugaron su papel en la economía de los vecinos de las ciudades y villas de la comarca altorriojana. La pesca constituía para un gran número de familias una actividad complementaria a partir de la cual se procuraban un alimento extra, aunque también existían algunas personas, los denominados «pescadores", especializados en ella, y que solían ser contratados por las autoridades concejiles para pescar en momentos señalados ${ }^{64}$. En los ríos Ebro, Tirón, Najerilla o Iregua se pescaban truchas, barbos, anguilas o loinas, que luego se vendían en los mercados de los núcleos urbanos. También existieron pesqueras en el Ebro a su paso por el término de Logroño, que además debieron de resultar bastante rentables, pues a finales del siglo xv algunos particulares trataron de monopolizar estas presas en detrimento del resto de los vecinos ${ }^{65}$. Junto a la pesca, también sabemos que la caza era practicada por los vecinos en los «pagos", sotos y montes de los términos rurales de los núcleos urbanos. En efecto, a través de la documentación municipal de Haro, sabemos que en el término de esta villa se cazaban perdices, conejos y liebres, utilizándose para ello lebreles y podencos, así como lazos, redes y hurones ${ }^{66}$. También eran objeto de caza "alimañas" como los lobos, que suponian un constante peligro para la cabaña ganadera, y por ello los concejos premiaban su captura ${ }^{67}$.

A lo largo del siglo xV y en el XVI los concejos urbanos tratarán de regular la pesca y la caza, sobre todo esta última actividad, un hecho que muy posiblemente haya que relacionar con la sobreexplotación que hacían algunos vecinos de este importante recurso económico ${ }^{68}$. Así lo hemos podido comprobar en Haro, pero también sabemos que ocurrió en Nájera, pues su hacienda concejil ingresaba dinero procedente de la renta denominada "veda de la caza", conformada por las multas impuestas a los ve-

64 «Este dia pago el dicho bolsero por mandado del alcalde e ommes buenos a los pescadores que venieron de pescar para el rey, mandaronles dar seis maravedis (A.M.H.: LC. 1430, cuenta de gastos en dinero), "a quatro dias de mayo fueron los pescadores a pescar por mandado de los alcaldes para faser presente a Diego Manrique, traxieron tres libras de truchas que costaron a quatro maravedis libra..." (A.M.N.: LC. 1439-40, cuenta de gastos en dinero).

65 Ernesto García Fernández y José Ramón Diaz dE DuRANa, “Las actividades económicas en Logroño..., o.c., p. 3.

66 Me remito a mi Tesis Doctoral: La sociedad altorriojana..., o.c., pp. 304-309.

67 "Este dia mando Diego Martines alcalde dar a los que traxieron los lobos dies maravedis" (A.M.N.: LC. 1455-56, cuenta de gastos en dinero).

68 Miguel Ángel LADERO QUESADA, "La caza en la legislación municipal castellana. Siglos XIII a xvilı, En la España Medieval / (1980), pp. 193-221, Manuel Fernando LADERo QueSADA, La ciudad de Zamora..., o.c., pp. 49-51, Carmen Fernández-Daza Alvear, la ciudad de Truijlo..., o.c., pp. 391-395. 
cinos que no respetaban la veda, y también de las penas impuestas a los pescadores ${ }^{69}$. Igualmente, en 1515 , tenemos constancia del envío de una provisión real al corregidor de Logroño para que se guardasen en la ciudad las ordenanzas existentes sobre la caza ${ }^{70}$. En Haro será en 1553 cuando se establezca por primera vez la veda de todo tipo de caza (con perros, redes, hurón y lazos) en los meses de marzo, abril y mayo, e igualmente se hará una reglamentación estricta de la pesca ${ }^{71}$.

\section{LAS ACTIVIDADES ARTESANALES}

La localización de los núcleos urbanos altorriojanos en el Camino de Santiago, representó para sus economías un importante impulso, permitiendo además una mayor diversificación de los sectores de actividad económica de sus habitantes ${ }^{72}$. En estos núcleos urbanos, desde el siglo xII se documentan diferentes artesanos, tales como pellejeros, herreros, tundidores, zapateros, sastres, e incluso artesanos que posteriormente no registramos en la Baja Edad Media, como orfebres (en Nájera) o caldereros y campaneros (en Santo Domingo de la Calzada) ${ }^{73}$. En esta ciudad, al filo del siglo xilI se registraban un buen número de oficios artesanales según un padrón conservado. Los nombres de algunos de estos artesanos nos revelan además su origen extranjero, lo que facilitará el desarrollo e impulso de las técnicas artesanales ${ }^{74}$.

Ya en la Baja Edad Media, los padrones fiscales que se han conservado, datados entre mediados del siglo XV e inicios del siglo XVI, nos confirman igualmente la existencia de diversos artesanos que ejercían sus actividades en las ciudades y villas altorriojanas, también en estos siglos ${ }^{75}$. Su número, bastante limitado, nos lleva a pensar que la mayoría de las profesiones no llegaron a adquirir la suficiente personalidad como para agrupar a demasiadas personas en torno a cada uno de los diferentes

69 FCo. Javier GoiCOLEA JULIÁN, "Las finanzas concejiles..., o.c., pp. 119-135 y A.M.N.: LC. 1439-40, cuenta de ingresos en dinero y LC. 1455-56, cuenta de ingresos en dinero.

70 A.M.L.: $16 / 37\left(2^{\circ}\right)$.

7 A.M.H.: Leg. 130 , letra G.

72 J. Ignacio RUIZ DE LA PEÑA, “La formación de la red urbana..., o.c., pp. 211-230.

73 Pascual Martínez Sopena, «Logroño y las villas riojanas..., o.c., p. 293.

74 El padrón puede verse en (Ciriaco LOPEZ DE SILANES y Eliseo SÁINZ RIPA, Colección Diplomática Calceatense. Archivo Catedral (Años 1125-1397)..., o.c., doc. $n^{\circledR} 8$ ).

75 Me refiero a los padrones fiscales de Logroño, Santo Domingo de la Calzada, Navarrete y Haro que se encuentran en el Archivo de la Real Chancilleria de Valladolid (Sala de Hijosdalgo, Serie Protocolos y Padrones). Sobre Logroño me remito al estudio de José Ramón Diaz DE DURANA y Ernesto García FERnAndez, Demografía y sociedad..., o.c.). 
ramos de actividad, y que tampoco lograron desarrollar una producción que superara los marcos locales y regionales ${ }^{76}$. En efecto, la documentación consultada nos ofrece muy pocos datos sobre la existencia de cofradías de oficios, procediendo los únicos testimonios de la ciudad de Logroño ${ }^{77}$. Además, un buen número de estos artesanos son propietarios de bienes agrarios, pues venden heredades a particulares y a las iglesias de Santa María de la Redonda y San Martín de Albelda. Dato que nos vuelve a poner de manifiesto el importante peso del sector rural en la economía del núcleo urbano más importante de la comarca altorriojana ${ }^{78}$.

Lo cierto es que la presencia de artesanos "especializados» en las ciudades y villas era de vital importancia para el buen funcionamiento económico de éstas. Por ello las autoridades concejiles, en el marco de una política económica tendente al autoabastecimiento, trataban de asegurar la presencia de artesanos en sus núcleos urbanos. En efecto, en Haro a lo largo del siglo Xv, las autoridades concejiles llevan a cabo una política de atracción de artesanos y de otros profesionales «especializados", a los cuales se concedían exenciones fiscales y otro tipo de ventajas, a cambio de avecindarse en la villa ${ }^{79}$. Política que nos indica igualmente las carencias de artesanos que tenía la villa, y que se hacian especialmente patentes en determinados sectores como el del metal ${ }^{80}$.

76 No obstante, conviene matizar la información que nos ofrecen estos padrones. En primer lugar, parece evidente que las cifras de vecinos artesanos son exageradas a la baja, pues no era obligatorio que quienes confeccionasen los padrones explicitaran la profesión de cada unidad fiscal, de tal forma que pudo haber errores y olvidos. En segundo lugar tampoco se menciona explícitamente la profesión de aquellos vecinos que se dedicaban a actividades económicas rurales, es decir, todos los demás a los que no se señala que ejercieran su actividad en el artesanado, el comercio o en profesiones liberales. Un hecho que vendría motivado por la dedicación de la mayoría de los vecinos a las actividades agrícolas y ganaderas, de tal forma que los empadronadores no les otorgaron la misma especificidad que al resto. En definitiva, somos conscientes de que la utilización de este sistema de trabajo con estas fuentes exagera al alza el peso de las actividades rurales, y por consiguiente habrá que utilizar las cifras obtenidas únicamente como indicadores de la realidad existente.

77 Margarita Cantera Montenegro, "Las cofradías religiosas en el Logroño medieval", Hispania Sacra, vol. $n^{2} 81-82$ (1988), pp. 167-178.

78 Ernesto Garcia Fernánoez y José Ramón DIAZ de Durana, “Las actividades económicas en Logroño..., o.c., p. 5.

79 En 1466 el concejo de Haro eximió de «pechos y facenderas" durante los diez primeros años a un pañero procedente de Pamplona, por avecindarse en la villa (A.M.H.: LA. 1466, sesión de concejo restringido del 26 de septiembre). Esta política de concesión de exenciones a artesanos especializados a cambio de fijar su residencia en el núcleo urbano también fue seguida en otros núcleos urbanos de la Corona de Castilla (Juan Carlos MARTIN CEA, El mundo rural castellano..., o.c., pp. 451-452, Manuel Fernando LADERo QuesadA, La ciudad de Zamora..., o.c., pp. 88-91).

80 Los profesionales del metal avecindados en Haro procedían principalmente de villas vascas como Mondragón, donde había un importante sector social dedicado a la producción de hierro y acero (José Ángel ACHÓN INSAUSTI, "A voz de Concejo..., o.c., pp. 288-291). 


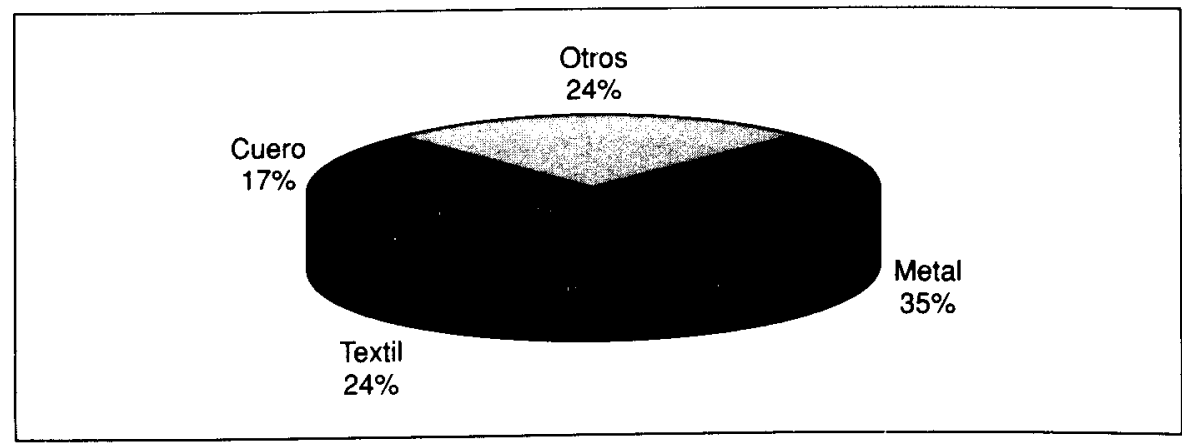

Fuente: A.M.H.: Libros de actas conservados.

Gráfico IV. Artesanos avecindados en Haro (s. XV, por sectores).

Los profesionales dedicados al sector textil, bien trabajando la materia prima ${ }^{81} 0$ confeccionando las prendas de vestir, representaban el contingente artesano más numeroso en las ciudades de Logroño, Santo Domingo de la Calzada y en la villa de Haro ${ }^{82}$. En los padrones de estos núcleos urbanos se inscribe a pañeros, tejedores, tundidores, tintoreros, sastres, costureros/as, sombrereros y juboneros, con lo que podemos apreciar un relativo grado de especialización técnica en relación a los procesos de elaboración, transformación y confección de las materias primas textiles. En Haro, en la segunda mitad del siglo XV tenemos documentados pisones "para adobar los pannos", y en esta misma villa y también en Santo Domingo de la Calzada, tiradores. En Logroño en el mismo período de tiempo sabemos que los tintoreros disponían de hornos propios para desarrollar su labor ${ }^{83}$. Por último, en Nájera también debian de estar bas-

81 La materia prima fundamental era la lana, proporcionada por la importante cabaña ovina que pastaba en los ámbitos territoriales de los núcleos urbanos, aunque suponemos que también se utilizarían fibras vegetales como el lino y el cáñamo para la fabricación de telas de lienzo, así como para la realización de cuerdas, cinchas y alforjas.

82 El textil también se constituyó en el sector artesanal más importante en los núcleos urbanos de otras comarcas de la Corona de Castilla (Paulino Iradiel MurugarRen, Evolución de la industria textil castellana en los siglos XIII-XVI, Salamanca, 1974, Ricardo CóRdOBA DE LA LLAVE, La industria medieval de Córdoba, Córdoba, 1990).

${ }_{83}$ Me remito a mi Tesis Doctoral: La sociedad altorriojana..., o.c., pp. 312-315, Ernesto García FERnÁnDEZ y José Ramón DIAZ dE DURANa, "Las actividades económicas en Logroño..., o.c., p. 7 , en Santo Domingo de la Calzada en los años finales del siglo XV, el Cabildo se opondrá a que un vecino termine de construir un tirador, alegando que lo hacía en solares de la Iglesia (Ciriaco LOPEZ DE SILANES y Eliseo SÁNZ RIPA, Colección Diplomática Calceatense. Archivo Catedral (14511499) y Archivo del Hospital (1431-1497)..., o.c., documentos del Archivo Catedral, doc. $\left.n^{2} 313\right)$. Los tiradores eran lugares donde se podían trabajar varios paños a un tiempo, con infinidad de 


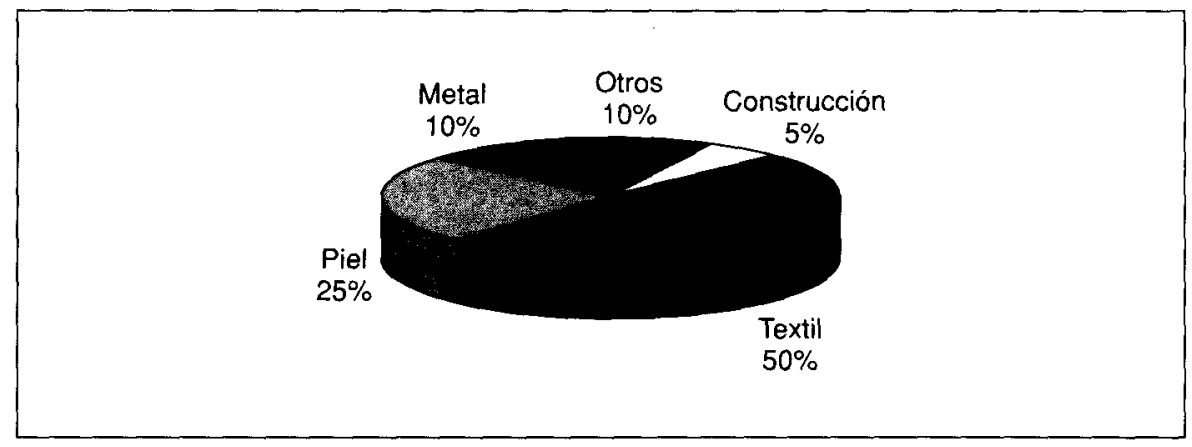

Fuente: José Ramón Diaz de Durana y Ernesto Garcia Fernandez, Demografía y sociedad.., o.c., p. 28.

Gráfico V. El artesanado de Logroño en 1454 (por sectores).

tante desarrolladas las actividades artesanales textiles, pues el concejo ponía en arriendo algunos años dos rentas relacionadas con este sector: la «rueda de los paños" y la renta de los «tintoreros» ${ }^{84}$. Todo ello nos permite constatar que en estos núcleos urbanos se desarrolló una pañería autóctona, de mala calidad, destinada a los sectores populares ciudadanos, pero junto a ella también una pañería de mejor calidad dirigida a los grupos sociales acomodados. Esta última se abastecería de paños llegados a las ferias que se desarrollaban en las ciudades y villas, y que serian acabados por los artesanos locales ${ }^{85}$.

La manufactura del cuero y de la piel seguía en importancia al sector textil según los padrones de Logroño, Santo Domingo de la Calzada y Haro, mientras en Navarrete se situaba incluso en primer lugar. La documentación nos informa sobre la existencia de albarderos, zurradores, silleros, vaineros o tamboreros, aunque dentro de este sector sobresalían los pellejeros, encargados de preparar la materia prima, y los zapateros, elaboradores del calzado. En Nájera, los fieles del concejo nombrados en

ramblas, bastidores de madera donde se sujetaba el paño, colgándolo y estirándolo con escarpias hasta que alcanzaba la anchura y longitud reglamentarias (Paulino Iradiel Murugarren, Evolución de la industria textil castellana.., o.c., p. 203).

84 A.M.N.: LC. $1439-40$ y 1455-56, cuentas de ingresos en dinero. El 28 de octubre de 1440 el buisero de concejo escribía en su Libro «este dia costaron de abaxar siete carretadas de madera del monte de Beçares al cargadero de las carretas para rueda del pison treynta e çinco maravedis" (A.M.N.: LC. 1439-40, cuenta de gastos en dinero).

85 Esta doble vertiente también se registraba en la ciudad deVitoria en los siglos XIV y XV (José Ramón Diaz de Durana, Alava en la Baja Edad Media. Crisis, Recuperación y Transformaciones Socioeconómicas (C. 1250-1525), Vitoria, 1986, pp. 230-237). 
1440 fueron un pellejero y un zapatero, y en 1477 también constatamos el nombramiento de un sillero como fiel ${ }^{86}$. En Logroño la vitalidad del grupo de los zapateros se manifiesta en la existencia de un cabildo, que reivindicará el monopolio de este oficio frente a los zapateros de origen judío a finales del siglo XIV y a lo largo del XV. Ya en tiempo de los Reyes Católicos la cofradía de los curtidores de Logroño, solicitaba a los monarcas tiempo suficiente para trasladar las tenerías fuera de la ciudad ${ }^{87}$.

También los judíos de Haro se dedicaron al trabajo del cuero, siendo propietarios de varias tenerías donde se curtía la piel, y un vecino de la judería, don Ça, será el representante de todos los zapateros de Haro en $1472{ }^{88}$. Igualmente, sabemos que en Santo Domingo de la Calzada, concretamente en el barrio de Malburguete, había tenerías, algunas de las cuales eran propiedad del Cabildo ${ }^{89}$. Los concejos controlaban la labor de estos artesanos, y así lo hemos podido comprobar a partir de nuestro estudio sobre la villa de Haro. En efecto, el concejo se encargaba de garantizar la calidad de la producción, ante las quejas que se registraban en determinados años ${ }^{90}$, e igualmente procuraba fomentar el consumo interno, prohibiendo en determinados momentos la venta de materia prima fuera de la villa ${ }^{91}$. Medidas similares sabemos que puso en práctica el concejo de Santo Domingo de la Calzada. Así, a partir de los Libros de actas municipales de los primeros años del siglo XVI, sabemos que en los contratos para el abasto de carne a la ciudad, entre otras condiciones las autoridades municipales obligaban a los carniceros a proporcionar la corambre

86 A.M.N.: LC. 1439-40, cuenta de ingresos en dinero y LC. 1476-77, acta de elección de oficios inserta.

87 Ernesto García FERnÁndez y José Ramón DIAZ DE DURANA, «Las actividades económicas en Logroño..., o.c., pp. 7-8, José Ramón Diaz dE DuRAna y Ernesto Garcia Fernández, Demografía $y$ sociedad..., o.c., p. 29 y Margarita CANTERA MONTENEGRO, "Las cofradías..., o.c., pp. 167-178).

88 Me remito a mi Tesis Doctoral: La sociedad altorriojana..., o.c., pp. 316-318.

89 Eduardo Azofra Agustin, "Desarrollo urbano de Santo Domingo de la Calzada en los tiempos medievales. Nuevas aportaciones históricas", Actas de la III Semana de Estudios Medievales de Nájera, Logroño, 1993, pp. 243-256 y Ciriaco LóPEZ dE SILANES y Eliseo SÁInz RIPA, Colección Diplomática Calceatense. Archivo Catedral (1400-1450)..., o.c., doc. $n^{2} 174$, Colección Diplomática Calceatense. Archivo Catedral (1451-1499) y Archivo del Hospital (1431-1497)..., 0.c., documentos del Archivo Catedral, doc. $\mathrm{n}^{\circ} 313$.

go Por ejemplo en 1466 (A.M.H.: LA. 1466, sesión de concejo restringido del 28 de noviembre). El control concejil de la producción de los zapateros y curtidores también fue seguido en otros núcleos urbanos de la Corona de Castilla, como Trujillo (Carmen Fernández-DazA Al_VEAR, La ciudad de Trujillo..., o.c., pp. 396-399) o Úbeda (Pedro Antonio PorRas ARBOLEDAS, "Las ordenanzas municipales. Algunas propuestas para su estudio y un ejemplo", Espacio, Tiempo y Forma, H. Medieval, vol. $n^{2} 7$ (1994), pp. 49-64).

9t «Se mando poner enbargo en los cueros de las vacas para que no los obiesen de vender fuera de la villa porque los ofiçiales de esta villa los an menester para provision de la villa..." (A.M.H.: L.A. 1472, sesión de concejo restringido del 16 de julio). 


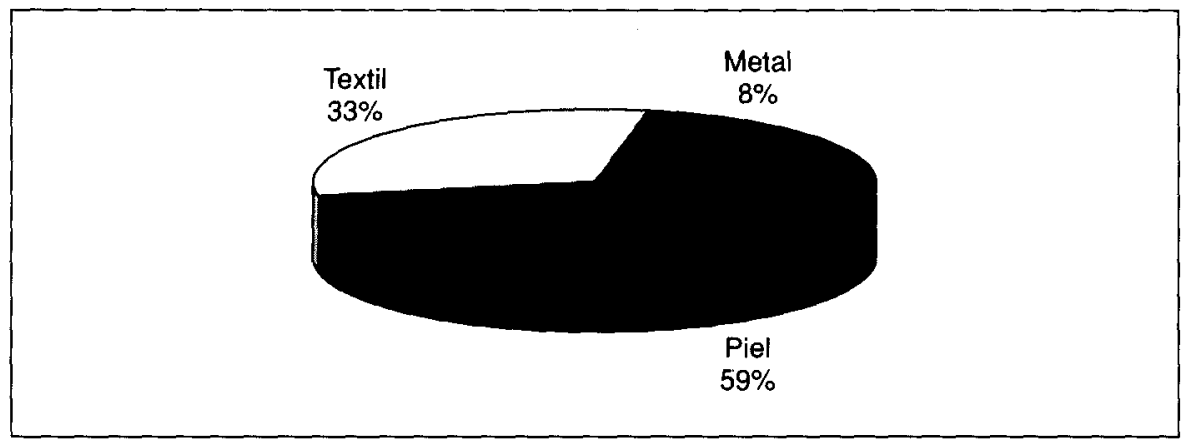

Fuente: A.R.CH.V.: Sala de Hijosdalgo, leg. 453-4, padrón fiscal de 1483.

Gráfico VI. El artesanado de Navarrete en 1483 (por sectores).

del ganado que mataran a los zapateros de la ciudad, debiendo de declarar éstos en un plazo de nueve días si querían hacerse con ella ${ }^{92}$.

A los sectores del textil y de la piel les seguía en importancia el sector del metal. Entre los artesanos del metal se encontraban los herreros, cerrajeros, armeros, coraceros, ballesteros o espaderos. Herreros y cerrajeros eran los encargados de abastecer a los núcleos urbanos de las herramientas para la labranza (azadas, azadones, legones, etc.), y de la realización de otras actividades propias del gremio como la fabricación de llaves y cerrajas para las puertas o candados, y argollas para las cárceles de las ciudades y villas ${ }^{93}$. La propia toponimia nos informa sobre la práctica de estas actividades en los núcleos urbanos altorriojanos. En efecto, así se pone de manifiesto en las calles de Herrerías y Cerrajerias de Logroño ${ }^{94}$, en la torre de la Ferrería en Nájera ${ }^{95}$ o en el término de la Ferrería en Santo Domingo de la Calzada ${ }^{96}$. En 1509 tenemos constancia que varios vecinos de Gallinero, aldea de esta última ciudad, pidieron permiso a las autoridades municipales de Santo Domingo de la Calzada para levantar una fragua en la referida aldea, alegando que ya tenían comprados los barquines ${ }^{97}$.

\footnotetext{
92 A.M.S. ${ }^{\circ}$ D. ${ }^{\circ}$ C. : LA. 1512 , sesión del 15 de abril.

93 "Este dia di a Juan çerrajero porque adobo dos candados e dos argollas de la carçel IX maravedis" (A.M.N.: LC. 1455-56, cuenta de gastos en dinero).

94 Ernesto Garcia Feanandez y José Ramón Diaz de Durana, "Las actividades económicas en Logroño..., o.c., p. 7.

95 Fco. Javier Garcia Turza, «Morfología de la ciudad de Nájera..., o.c., p. 86.

96 Ciriaco LOPEZ DE SILANES y Eliseo SÁINZ RIPA, Colección Diplomática Calceatense. Archivo Catedral (Años 1125-1397)..., o.c., p. 300.

97 A.M.S. ${ }^{9}$ D. ${ }^{9}$ C. ${ }^{a}$ : L.A. 1509 , sesión del 10 de mayo.
} 


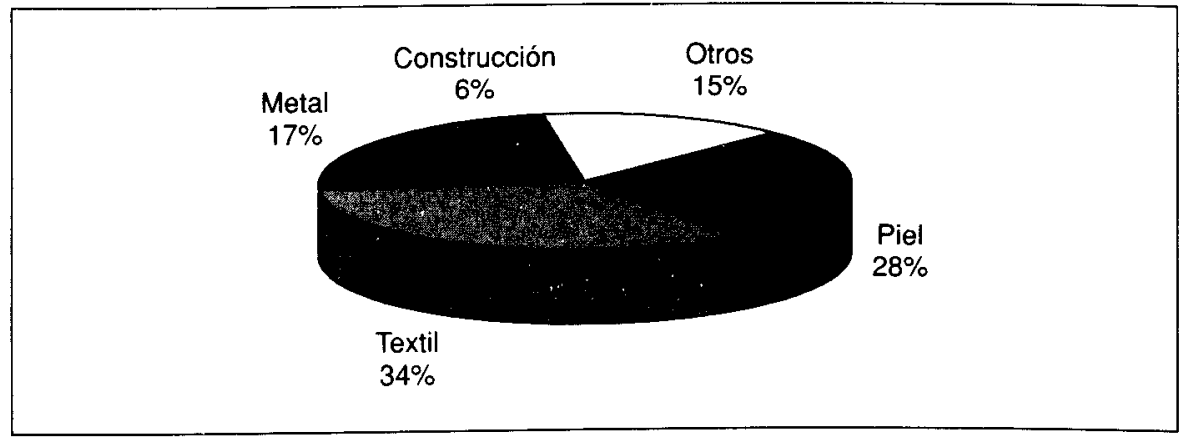

Fuente: A.R.CH.V.: Sala de Hijosdalgo, leg. 20-1, padrón fiscal de 1503.

Gráfico VII. El artesanado de Santo Domingo de la Calzada en 1503 (por sectores).

El importante papel jugado por estos artesanos, hacía que los concejos no dudasen en concederles ventajas y ayudas para que fijasen su residencia en el núcleo urbano. De esta forma, en 1477, el concejo de Haro concedió una ayuda de diez reales de plata a un herrero para que no se fuera de la villa, e igualmente solían ser frecuentes las concesiones de ayudas para la instalación de ferrerías y fraguas ${ }^{98}$. Los profesionales encargados de la realización de armas (armeros, ballesteros o espaderos), también cumplían una importante misión, pues la guerra afectaba frecuentemente a una comarca que se encontraba situada en la frontera con el reino de Navarra. En efecto, el disponer de un arsenal abundante y en buen estado de lanzas, corazas, paveses, ballestas, viratones o espadas, era trascendental para garantizar la seguridad de los núcleos urbanos. Incluso, en Haro, hemos podido comprobar que su concejo establecerá contratos con especialistas armeros no residentes en la villa, especialmente coraceros, para la realización de estos útiles en el núcleo urbano ${ }^{99}$.

Además de estos tres sectores fundamentales, también documentamos en los núcleos urbanos altorriojanos otros profesionales artesanos, entre los que destacaban los pertenecientes a la construcción. Éstos estaban representados fundamentalmente por los canteros, carpinteros, tejeros, yeseros y caleros. Los canteros se dedicaban por un lado a sacar y labrar

98 Me remito a mi Tesis Doctoral: La sociedad altorriojana..., o.c., pp. 319-322.

99 El 6 de mayo de 1470 el concejo de Haro realizó un contrato con el coracero Juan Martínez para que viniera a la villa a hacer corazas, comprometiéndose el concejo a darle casa para desempeñar su trabajo, así como posada para él, su familia y su cabalgadura (A.M.H.: L.A. 1470, sesión de concejo amplio de la fecha indicada). 


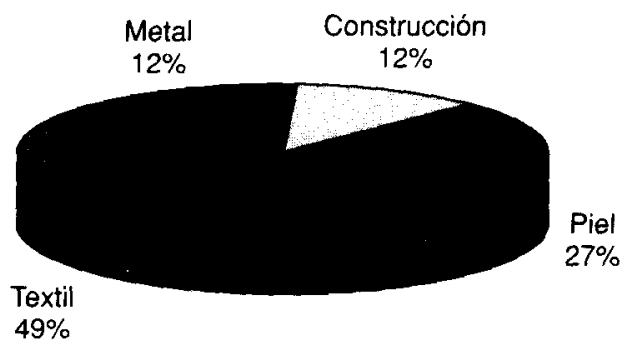

Fuente: FCo. Javier GoICOLEA JULIAN, La sociedad attorriojana.., o.c., p. 319.

Gráfico VIII. El antesanado de Haro en 1518 (por sectores).

piedra de las canteras para proveer a las diferentes obras que se realizaban en las ciudades y villas, e igualmente se encargaban de realizar las frecuentes reparaciones en las casas de los vecinos, así como en las murallas, puentes o torres de los núcleos urbanos ${ }^{100}$. Junto a los canteros, los carpinteros eran los otros artesanos indispensables en la construcción, puesto que la madera seguía siendo todavía a finales de la Edad Media un elemento constructivo de primer orden. Su empleo en las casas, muralla, molinos (carpinteros de molinos), puentes, etc., hacía que el trabajo de los carpinteros fuera muy solicitado por los vecinos y por los propios concejos, que los contrataban frecuentemente para la realización de obras públicas ${ }^{101}$. Finalmente, los tejeros se encargaban de hacer tejas en las tejerías situadas en los términos de los núcleos urbanos, los yeseros realizaban cal, mientras los caleros trabajaban en las caleras haciendo cal.

Los padrones también nos informan sobre otros profesionales artesanos que trabajaban en los núcleos urbanos. Entre éstos estaban los comporteros, que hacían comportas para transportar la uva, cuberos que realizaban las cubas donde los vecinos guardaban el vino, asteros encargados de realizar útiles de madera para las labores agrícolas, o tor-

\footnotetext{
100 El gasto concejil en obras públicas, en el cual se incluían los salarios pagados a canteros, carpinteros, etc., fue en progresión creciente en la comarca altorriojana (Fco. Javier GoicOLEA JULIAN, «Finanzas concejiles..., o.c.). En los Libros de actas del concejo de Haro se han conservado varios contratos entre canteros y el concejo para sacar y labrar piedra (me remito a mi Tesis Doctoral: La sociedad altorriojana..., o.c., pp. 322-324).

${ }_{10}$ FCo. Javier GoICOLEA JULIẢN, «Finanzas concejiles..., o.c. y «Las finanzas concejiles y la fiscalidad de Nájera..., o.c., pp. 119-135.
} 
neros que producian bienes de consumo para la vida cotidiana de la población. También artesanos que realizaban recipientes de cerámica, los olleros, cuya presencia en Logroño queda atestiguada por la calle denominada de Ollerías, e incluso cerámica vidriada como la que producían los mudéjares de Haro ${ }^{102}$. Igualmente, hemos podido constatar la presencia de oficios artesanales de carácter artístico como libreros, entalladores, pintores y plateros. Estos últimos se encargaban de hacer los pesos utilizados en las tiendas y carnicerías, así como de afinar los instrumentos de medición; pero también producian objetos suntuarios destinados a las iglesias y a los sectores sociales acomodados de las ciudades y villas ${ }^{103}$.

Otro de los temas a los que vamos a realizar una aproximación, es el referido a las relaciones entre las actividades artesanales y el espacio urbano ${ }^{104}$. En efecto, a partir de los padrones también podemos conocer la distribución de la población artesana en el espacio urbano de Logroño, Santo Domingo de la Calzada y Haro. En Logroño, a través del estudio de José Ramón Díaz de Durana y Ernesto García Fernández, sabemos que la mayoría de los vecinos dedicados a las actividades artesanales y comerciales, se encontraban avecindados en el quiñón de la Rúa de las Tiendas y en el quiñón de la Rúa Mayor. La ciudad de Logroño se desarrolla precisamente a partir de estas dos circunscripciones, de tal forma que la situación del siglo $\mathrm{xv}$ recoge la herencia del esplendor anterior logrado gracias al Camino de Santiago ${ }^{105}$. En Santo Domingo de la Calzada, sin embargo, parece ocurrir lo contrario. En efecto, a partir del padrón de 1503 , constatamos que el contingente principal de artesanos se concentraba en el barrio de la Cal del Medio, seguido del barrio de la Puebla, el más poblado, y de los barrios Nuevo y Viejo. Podemos comprobar, por tanto, cómo la población artesana se concentraba a fines de la Edad Media principalmente el los barrios más nuevos surgidos de la expansión

102 Enrique CANTERA MONTENEGRO, “La comunidad mudéjar de Haro en el siglo XV", separata de En la España Medieval IV (1984), pp. 157-173.

103 En Logroño, en el padrón de 1454 se inscriben cinco plateros (José Ramón Diaz DE DUrana y Ernesto Garcia FernánDEZ, Demografía y sociedad..., o.c., p. 28), en Santo Domingo de la Calzada dos en el padrón de 1503 (A.R.CH.V.: Sala de Hijosdalgo, leg. 20-1), y en Haro constatamos por lo menos a dos plateros en los años finales del siglo xv (me remito a mi Tesis Doctoral: La sociedad altorriojana..., 0.c., p. 325).

104 Un buen ejemplo puede verse en el estudio dedicado por Antonio COLLANTES DE TERAN a la ciudad de Sevilla, "Interrelaciones entre espacio urbano y actividades artesanales: Algunas consideraciones a partir de la imagen que ofrece la Sevilla bajomedieval", La Ciudad Medieval, Valiadolid, 1996, pp. 83-106.

105 José Ramón Diaz de Durana y Ernesto Garcia Fernandez, Demografia y sociedad..., o.c., pp. 30-34. 
urbana bajomedieval ${ }^{106}$. Por último, en Haro, a inicios del siglo XVI el barrio donde vivía el mayor número de artesanos era el núcleo más antiguo de la población, es decir la media villa de San Martín, aunque seguido del barrio del Arrabal, donde residían la mayor parte de los artesanos del metal, situándose en último lugar la media villa de Santo Tomás. En cuanto a la distribución en la media villa de San Martín, la calle en la que estaban avecindados más artesanos era la calle de la Mezquita, seguida de la calle de San Martín, y ya a una distancia bastante mayor se encontraban las calles de la Paz, Portillo y Carra la Mota ${ }^{107}$.

Tabla I. Distribución de los artesanos en el espacio urbano de Santo Domingo de la Calzada en 1503

\begin{tabular}{lccccccc}
\hline & $\begin{array}{c}\text { TOTAL } \\
\text { VECINOS }\end{array}$ & $\begin{array}{c}\text { TOTAL } \\
\text { ARTESANOS }\end{array}$ & $\begin{array}{c}\text { SECTOR } \\
\text { TEXTIL }\end{array}$ & $\begin{array}{c}\text { SECTOR } \\
\text { PIEL }\end{array}$ & $\begin{array}{c}\text { SECTOR } \\
\text { METAL }\end{array}$ & $\begin{array}{c}\text { SECTOR } \\
\text { CONSTRUC. }\end{array}$ & $\begin{array}{c}\text { OTROS } \\
\text { ARTESANOS }\end{array}$ \\
\hline $\begin{array}{l}\text { BARRIO } \\
\text { VIEJO }\end{array}$ & 95 & 5 & 4 & 1 & - & - & - \\
\hline $\begin{array}{l}\text { BARRIO } \\
\text { NUEVO }\end{array}$ & 96 & 8 & - & 5 & 2 & - & 1 \\
\hline $\begin{array}{l}\text { CAL DEL } \\
\text { MEDIO }\end{array}$ & 132 & 21 & 6 & 5 & 4 & 1 & 5 \\
\hline LA PUEBLA & 224 & 13 & 6 & 2 & 2 & 2 & 1 \\
\hline
\end{tabular}

Fuente: A.R.CH.V.: Sala de Hijosdalgo, leg. 20-1, padrón fiscal de 1503.

Para finalizar vamos a hacer referencia a un padrón de la villa de $\mathrm{Na}$ varrete fechado en el año 1525, y que presenta la particularidad de que los vecinos del núcleo urbano aparecen inscritos en cada una de las cuadrillas en que se estructuraba esta villa. Cuadrillas que reciben las denominaciones de Encima de la villa, el Pozo, el Doctor, la Cuesta, Santa María y San Juan. La cuadrilla, como hemos estudiado en otro lugar ${ }^{108}$, constituía la célula básica de la organización comunitaria de los vecinos de los núcleos urbanos de La Rioja Alta (así lo constatamos en Haro, Santo Do-

106 Eduardo Azofra Agustín, «Desarrollo urbano de Santo Domingo de la Calzada..., o.c., pp. 243-256. También oferece información del urbanismo de Santo Domingo de la Calzada Jean PASSINI, "El medio urbano como informador arqueológico medieval", Actas de la III Semana de Estudios Medievales..., o.c., pp. 89-102, especialmente pp. 92-94, "El espacio urbano a lo largo del Camino de Santiago", Actas de la XX Semana de Estudios Medievales de Estella, Pamplona, 1994, pp. 247-269.

107 Fco. Javier GoicoleA JULIÁN, La sociedad altorriojana..., o.c., pp. 311 y 319.

108 FCo. Javier GoICOLEA JULIÁN, "Concejos urbanos en La Rioja Alta..., o.C. 
mingo de la Calzada, Nájera y Navarrete). En base a ellas se organizaban las "facenderas" o labores concejiles, se estructuraba la milicia concejil, la defensa de los núcleos urbanos, etc. Desconocemos la correspondencia que pudieron tener las cuadrillas con la organización urbana de la villa en base a barrios y calles ${ }^{109}$, y únicamente en el caso de la cuadrilla de Encima de la villa se hace mención expresa al comienzo del empadronamiento de los vecinos "començando por el rabal». La fuente resulta de un interés indudable para el estudio de la sociedad de Navarrete de finales de la Edad Media e inicios de la Moderna, pues en cada una de las cuadrillas se contabilizan los pecheros o «berederos", los «libertados", las viudas y los hidalgos. Desde el punto de vista de los oficios artesanales, podemos comprobar en la tabla $n^{\circ} I I$, que son pocos los profesionales que se inscriben, los más en las cuadrillas del Pozo y Santa María, aunque su número es algo mayor al de los inscritos en los padrones de 1483 y $1504{ }^{110}$. La razón, como ya hemos expuesto en líneas anteriores, habría que buscarla en que los empadronadores no explicitaron la profesión de todos los vecinos artesanos, pues si no no se entiende que en el sector del cuero no se mencione a ningún profesional, cuando en 1483 se inscribía a cuatro pellejeros y un zapatero, y en 1504 a tres pellejeros y cuatro zapateros ${ }^{111}$.

Tabla II. Distribución de los artesanos de Navarrete en las cuadrillas de la villa en 1525

\begin{tabular}{lcccccc}
\hline & $\begin{array}{c}\text { TOTAL } \\
\text { VECINOS }\end{array}$ & $\begin{array}{c}\text { TOTAL } \\
\text { ARTESANOS }\end{array}$ & TEXTIL & CUERO & METAL & OTROS \\
\hline $\begin{array}{l}\text { ENCIMA DE } \\
\text { LA VILLA }\end{array}$ & 68 & 2 & 1 & - & 1 & - \\
\hline EL POZO & 67 & 4 & 3 & - & 1 & - \\
\hline EL DOCTOR & 65 & 2 & 1 & - & - & 1 \\
\hline SAN JUAN & 65 & 2 & 1 & - & 1 & - \\
\hline LA CUESTA & 67 & 2 & - & - & 1 & 1 \\
\hline SANTA MARÍA & 61 & 4 & 3 & - & - & 1 \\
\hline
\end{tabular}

Fuente: A.R.CH.V.: Sala de Hijosdalgo, leg. 95-3.

109 Jean PASSINI hace algunas referencias al urbanismo del Navarrete, pero las noticias que ofrece son muy limitadas "El Camino de Santiago en La Rioja: trazados y núcleos", Actas de la IV Semana de Estudios Medievales de Náera, Logroño, 1994, pp. 121-133.

110 A.R.CH.V.: Sala de Hijosdalgo, leg. 453-4.

111 Ibidem. 


\section{EL MERCADO LOCAL}

Al igual que el resto de las ciudades y villas de la Corona de Castilla, también los núcleos urbanos altorriojanos irán convirtiéndose desde la época foral en centros mercantiles reguladores de su entorno rural ${ }^{112}$. Su situación en el Camino de Santiago favorecerá el impulso comercial, incentivado además por las concesiones y privilegios que los diferentes monarcas irán concediendo a estas ciudades y villas ${ }^{113}$. En efecto, a lo largo de la Plena Edad Media los núcleos urbanos altorriojanos se benefician de exenciones de impuestos mercantiles como el portazgo, e igualmente de franquicias económicas en forma de mercados, y ferias como las concedidas por Alfonso $X$ a Santo Domingo de la Calzada en 1270 o por Fernando IV a Haro (tres) en 1295 y a Logroño (dos) en $1314^{114}$. La toponimia urbana nos confirma este impulso comercial. En Logroño documentamos el quiñón del Mercado y la Rúa de las Tiendas, así como las calles Triperías, Carnicerías, Mercaderes o del Mercado, en Nájera los barrios de las Tiendas y del Mercado, y en Santo Domingo de la Calzada el barrio del Mercado ${ }^{115}$.

A través de los mercados y de las ferias, los núcleos urbanos se abastecían de todo tipo de productos artesanales y de alimentos, pero además los concejos también se encargaban de mantener todo el año varias tiendas, en las cuales los vecinos podían adquirir productos alimenticios de primera necesidad. En el marco de una política claramente proteccionista, el abastecimiento de la ciudad o villa, fue sin duda uno de los temas prioritarios que tenían que resolver las autoridades ciudadanas ${ }^{116}$. En efecto,

112 Miguel Ángel LADERO QUESADA, «Economía mercantil y espacio urbano: ciudades de la Corona de Castilla en los siglos $\times \|$ a Xv", Boletín de la Real Academia de la Historia, vol. $n^{2} \mathrm{CXCl}$ (1994), pp. 235-293.

113 Pascual Martínez Sopena, «Logroño y las villas riojanas..., o.c., pp. 281-295.

114 J. Ignacio RUIZ DE LA PEŃA, “La formación de la red urbana..., o.c. y Enrique CANTERA MONTENEGRO, "Franquicias regias a ciudades y villas riojanas en el marco de la política repobladora de Alfonso X", Berceo, n 114-115 (1988), pp. 105-118.

115 Pascual Martinez Sopena, “Logroño y las villas riojanas..., o.c., p. 290, Ernesto Garcia Fernandez y José Ramón Díz de Durana, "Las actividades económicas..., o.c., p. 9, José Ramón Diaz de Durana y Ernesto Garcia Fernánoez, Demografia y sociedad..., o.c, p. 17, Fco. Javier Garcia Turza, «Morfología de la ciudad de Nájera..., o.c., pp. 63-88, Eduardo Azofra Agustin, "Desarrollo urbano de Santo Domingo de la Calzada..., o.c., p. 253.

t16 Son numerosos los estudios que se han realizado sobre el abastecimiento de los núcleos urbanos de la Corona de Castilla, muchos de los cuales forman parte de las monografías dedicadas a ciudades y villas. Aqui me limitaré a citar algunos otros: César GonzÁLEZ MinguEZ, "Algunos aspectos del abastecimiento de Vitoria en la Edad Media", Actas del / Congreso de Estudios His. tóricos: Vitoria en la Edad Media, Vitoria, 1982, pp. 562-602, Beatriz ARizAGA BolumBuru, "La alimentación en el País Vasco en la Baja Edad Media: el caso de Guipúzcoa", Manger et boire au 
la obtención de alimento constituía para el hombre medieval un serio problema, motivado por variados factores. La dependencia de las condiciones naturales, el empleo de una tecnología atrasada que daba lugar a unos rendimientos y una productividad escasa, la cotidianidad de la guerra y las crisis periódicas de subsistencias, hacían que el fantasma del hambre estuviera continuamente presente en el transcurso de la vida de las mujeres y hombres del Medievo.

Los padrones fiscales que se han conservado mencionan a los diferentes profesionales, que se dedicaban a la venta de estos productos alimenticios de primera necesidad en las ciudades y villas altorriojanas. Así, los empadronadores registran a carniceros, tenderos, panaderos, fruteros, boticarios o pimenteros. También tenemos referencias a taberneros, pues aunque los núcleos urbanos altorriojanas destacan en estos momentos por la producción y exportación de vino ${ }^{117}$, como hemos podido comprobar en Haro y en Santo Domingo de la Calzada, sus concejos se preocupaban de reservar todos los años un buen número de cántaras para la provisión de los vecinos. En efecto, el concejo de Haro se encargaba de mantener anualmente en la villa, una, dos o tres tabernas de vinos tinto y blanco para el consumo interno. La importación de vino "de fuera" sólo podía hacerse con licencia concejil, que era concedida en momentos de gran necesidad, como sucedió en 1461, año en que se tuvo que traer "vino de

Moyen Age, Nice, 1984, vol. $n^{2}$ II, pp. 197-208, “El abastecimiento de las villas vizcainas medievales: política comercial de las villas respecto al entorno y a su interior", Actas del Congreso La Ciudad Hispánica durante los siglos XII al XVI, Madrid, 1985, vol. $n^{2}$ I, pp. 293-316, Antonio CoLLANTES DE TERÁN, "La red de mercados de abasto de Sevilla: permanencias y transformaciones (siglos XV y XVI)", Actes du Colloque organisé par la Junta de Comunidades de Castilla-La Mancha et la Casa de Velázquez: "Tolède et l'expansion urbaine en Espagne (1450-1650)», Madrid, 1991, pp. 225-236, Ricardo IZQUIERDO BENITO, “La actividad comercial en Toledo a fines de la Edad Media (1450-1475)", Actes du Colloque organisé par la Junta..., o.c., pp. 137-157, Juan Antonio BonaChÍA HERNANDO, “Abastecimiento urbano, mercado local y control municipal: La provisión y comercialización de la carne en Burgos (siglo Xv)", Espacio, Tiempo y Forma, H." Medieval, vol. $n^{9}$ 5 (1992), pp. 85-162, Ernesto GARCía FERNÁNDEZ, "La Cofradía de San Juan de "Arramele" y las ordenanzas de Tolosa de 1501", Sancho el Sabio, vol. $n^{2} 4$ (1994), pp. 301-312.

117 Entre los compradores de vino de los núcleos urbanos altorriojanos destacaban las ciudades de Burgos y Vitoria (Yolanda GuerRero NavarRete, «El papel de la Rioja en la configuración del ámbito económico y jurisdiccional de Burgos. La relación de ambas áreas geo-económicas en la Edad Media", Actas del // Coloquio sobre la Historia de la Rioja, Logroño, 1986, vol. $n^{2}$ I, pp. 257-263 y César GonzÁlez Minguez, «Algunos aspectos del abastecimiento de Vitoria..., o.c., pp. 562-602). Los debates y pleitos que mantuvieron las ciudades y villas altorriojanas por el control de los mercados del vino, especialmente con las villas también riojanas de Laguardia y San Vicente la Sonsierra, nos ponen de manifiesto la importancia de este comercio (Ernesto GaRcia FERNÁNDEZ, «Economía y sociedad de la Comunidad de Villa y Tierra de Laguardia..., o.c., pp. 387-403, Fco. Javier GoICOLEA JULIÁN, "La política económica del concejo de Haro a finales de la Edad Media: la comercialización del vino", Espacio, Tiempo y Forma, H. Medieval, vol. ne 7 (1994), pp. 103-119). 
fuera para probision del pueblo" ${ }^{118}$. Licencias que también sabemos que otorgaba el concejo de Santo Domingo de la Calzada ${ }^{119}$, que igualmente se encargaba de garantizar la provisión de las tabernas de la ciudad: «e quedo por condiçion que el dicho Juan de Çaldo aya de tener dos tabernas, la una en la Puebla e la otra donde vybe el dicho Çaldo" ${ }^{120 .}$

Los concejos también regulaban el abasto de carne mediante el arrendamiento de las carnicerías a los carniceros en régimen de monopolio, previo establecimiento de un contrato en el que los concejos fijaban los precios y la forma en que se debía llevar a cabo la venta de los diferentes productos cárnicos ${ }^{121}$. A partir de los Libros de actas municipales de Haro y Santo Domingo de la Calzada, conocemos las características de estos contratos (ver tablas III y IV). Los arrendatarios se obligaban a proveer de carne los bancos de la carniceria, normalmente por un período de un año. Debían proporcionar carne de vaca y carnero, especificándose también en ocasiones el abasto de carne de oveja y cabrón. La carne de cordero era más apreciada, siendo los precios siempre superiores a los de la carne de vaca. Esta última era también más escasa, pues la cabaña de ganado vacuno "terreño" era más reducida que la del ganado ovino. De ahí que en algu-

118 FCo. Javier GoICOLEA JULIÁN, “La política económica del concejo de Haro..., o.c., pp. 103119.

119 A.M.S. ${ }^{9}$ D. ${ }^{\circ}$ C.. : LA. 1509 , sesión del 2 de junio.

120 A.M.S. ${ }^{q}$ D. ${ }^{\circ}$ C..$^{a}$ : LA. 1508 , sesión del 13 de julio. En la sesión del 15 de julio se pujaron los precios del vino que se vendía en las tabernas de la ciudad.

121 Sobre las carnicerías de Logroño (Ernesto Garcia FERnández y José Ramón Díaz DE DURANA, "Las actividades económicas en Logroño..., o.c., y sobre las carnicerías de Haro y Nájera mi Tesis Doctoral: La sociedad altorriojana..., o.c., pp. 329-343 y A.M.N.: LC. 1439-40, 1455-56 y 1476-77). En Santo Domingo de la Calzada ya constatamos a dos carniceros en el padrón citado del siglo XIII (Ciriaco LoPEZ DE SILANes y Eliseo SÁInz RIPA, Colección Diplomática Calceatense. Archivo Catedral (1125-1397)..., o.c., doc. $\left.n^{\circ} 8\right)$, e igual número de carniceros se inscriben en el barrio de la Cal del Medio según un padrón de inicios del siglo XVI (año 1512?) (A.R.CH.V.: Sala de Hijosdalgo, leg. 20-1). Los Libros de actas del concejo de Santo Domingo de la Calzada, también nos ofrecen abundante información sobre los contratos establecidos entre las autoridades municipales y los carniceros para el abasto de carne a la ciudad. He consultado los Libros de actas comprendidos entre los años 1508 a 1513. A partir de los Libros de cuentas concejiles de Haro y Nájera podemos comprobar cómo los concejos se preocupaban de mantener en buen estado los edificios públicos destinados a carnicerías «Este dia di a Diego de Ruego a destajo a retejar e adobar la carnesçeria..." (A.M.N.: LC. 1439.40, cuenta de gastos en dinero). Sobre el abasto en general (contratos de obligación, fijación de precios, normas de venta, etc.) me remito a mi Tesis Doctoral sobre Haro, donde he estudiado con detalle todas estas cuestiones. El sistema de uobligados" también fue utilizado por el concejo de Burgos a lo largo del siglo XV, aunque aquí junto al propio concejo también habia otros propietarios de tablas y suelos de las carnicerías, como el cabildo, el monasterio de las Huelgas o particulares (Juan Antonio BonACHiA HERNANDO, "Abastecimiento urbano..., o.c., pp. 85-162). Un caso más extremo se daba en la villa vasca de Tolosa en los años finales del siglo $\mathrm{xV}$, donde las carnicerías se encontraban en una situación de privacidad, teniendo cada carnicero las carnicerías en sus propias casas (Ernesto GARCIA FERNÁnDEZ, "La Cofradía de San Juan..., o.c., pp. 301-312). 
nos años se especifique que hasta el día de San Juan la provisión sea sólo de cordero, y a partir de esta fecha se provea una tabla con carne de vaca, una vez que llegaran a la ciudad las vacas "extremeñas» ${ }^{122}$.

Tabla III. Contratos para servir la carnicería y la tienda de Haro en 1461

\begin{tabular}{|c|c|c|c|c|}
\hline & TITULARES & DURACIÓN & PRODUCTOS & PRECIOS \\
\hline CARNICERÍA & $\begin{array}{l}\text { SALOMÓN } \\
\text { DE LEIVA }\end{array}$ & $\begin{array}{c}\text { DESDE EL } 7 \text { DE } \\
\text { OCTUBRE DE } 1461 \\
\text { HASTA } \\
\text { CARNESTOLENDAS } \\
\text { DE } 1462 \\
\end{array}$ & $\begin{array}{l}\text { VACA Y } \\
\text { CARNERO }\end{array}$ & $\begin{array}{l}\text { CUARTA DE } \\
\text { CARNERO } \\
7 \text { MRS. } \\
\text { CUARTA DE } \\
\text { VACA } 5 \text { MRS. }\end{array}$ \\
\hline TIENDA & $\begin{array}{c}\text { MARTÍN } \\
\text { SÁNCHEZ } \\
\text { DE TRICIO } \\
\text { PEDRO } \\
\text { LÓPEZ } \\
\text { DE OLLAURI }\end{array}$ & $\begin{array}{l}\text { DESDE EL PRIMER } \\
\text { DİA DE CUARESMA } \\
\text { EN UN AÑO, MEDIA } \\
\text { TIENDA CADA UNO }\end{array}$ & $\begin{array}{l}\text { CONGRIO } \\
\text { MORENA } \\
\text { PESCADO DE } \\
\text { GALICIA } \\
\text { PESCADO DE } \\
\text { LA COSTA } \\
\text { SARDINAS } \\
\text { ACEITE } \\
\text { CANDELAS }\end{array}$ & $\begin{array}{l}\text { LIBRA DE } \\
\text { CONGRIO } \\
10 \text { MRS. } \\
\text { LIBRA DE } \\
\text { MORENA } \\
9 \text { MRS. } \\
\text { LIBRA DE } \\
\text { PESCADO } \\
\text { DE GALICIA } \\
\text { Y DE LA COSTA } \\
4 \text { MRS. Y } 2 \\
\text { CORNADOS } \\
\text { LIBRA DE } \\
\text { SARDINAS } \\
\text { BLANCAS Y } \\
\text { ARENCADAS } \\
2 \text { MRS. } \\
\text { LIBRA DE } \\
\text { ACEITE } 6 \text { MRS. } \\
\text { LIBRA DE } \\
\text { CANDELAS } \\
6 \text { MRS. }\end{array}$ \\
\hline
\end{tabular}

Fuente: A.M.H.: LA. 1461.

Pero, además, en los contratos también se especificaban otras cuestiones. En Haro, entre otras disposiciones se establecía cuál debía ser la

122 A.M.S. ${ }^{\circ D} .{ }^{9}$ C. $:$ : LA. 1510 , sesión del último día de febrero y mi Tesis Doctoral: La sociedad altorriojana..., o.c., pp. 329-336 y 758-771. Los ganados "terreños" eran los procedentes de los rebaños del término rural y de la comarca, mientras los eextremeños" eran traídos por los carniceros de lugares más lejanos. 
manera adecuada de cortar y expender las piezas de vaca y carnero, la concesión de pastos francos de la villa para el ganado de los carniceros y la prohibición de poner carnicerías en las aldeas del término rural. Igualmente se fijaban las penas por la utilización de pesos "faltos", por no respetar los precios, por cortar mal la carne y por venderla en mal estado, y además se estipulaban los impuestos que debían pagar los carniceros. Finalmente, los carniceros se comprometían también a traer los toros para las corridas que se celebraban durante las fiestas, así como a proporcionar carnero castrado a los enfermos ${ }^{123}$. Similares disposiciones se establecian en la ciudad de Santo Domingo de la Calzada. Las más novedosas con respecto a Haro hacian referencia a la prohibición de que el arrendatario de la carnicería vendiese carne destinada a la provisión de la ciudad a otras villas y lugares, la prohibición de matar carneros cojudos a partir del día de San Pedro, la obligatoriedad de poner "cortadores" o despachadores de carne en las tablas, la obligatoriedad de vender la corambre del ganado sacrificado a los zapateros de la ciudad, o el deber de tener abierta la carnicería los sábados y domingos ${ }^{124}$.

En cuanto a las tiendas donde se vendía el pescado, el aceite y otros "averios", en Haro hemos comprobado que su concejo establecía con los tenderos unos contratos de "obligación", casi siempre anuales, similares a los suscritos con los carniceros, arrendándoles ocasionalmente locales para la venta de estos productos, como casas o la botica, que como podemos ver en el gráfico $n^{0} 9$, también era arrendada anualmente por el concejo de Nájera ${ }^{125}$. En estos contratos, tal y como hemos podido comprobar en Haro y en Santo Domingo de la Calzada, se fijaban toda una serie de requisitos que los tenderos debían cumplir. Entre ellos las formas de venta: por «menudo" y "grueso», así como la posibilidad de vender los productos tanto a los vecinos de la villa como a los de fuera, los límites competenciales con los buhoneros, la prohibición de comprar mercancías fiadas, la obligatoriedad de tener abastecidas las tiendas durante todo el año, la prohibición de utilizar pesos falsos y faltos, el pago de la alcabala - la obligatoriedad de que los fieles estuvieran presentes en todas las compras realizadas por los tenderos dentro de la jurisdicción del núcleo urbano ${ }^{126}$. El pescado tenía un papel importante en la dieta alimenticia,

123 Me remito a mi Tesis Doctoral: La sociedad altorriojana..., o.c., pp. 329-336.

124 A.M.S. ${ }^{2}$ D.C $^{9}$ : LA. 1508, sesión del 18 de julio y LA. 1512, sesión del 15 de abril.

125 Me remito a mi Tesis Doctoral: La sociedad altorriojana..., 0.c., pp. 336-343. En el padrón fiscal de Navarrete del año 1504 también se inscribe a un tendero (A.R.CH.V.: Sala de Hijosdalgo, leg. 453-4).

${ }_{126}$ Me remito a mi Tesis Doctoral: La sociedad altorriojana..., o.c., pp. $336-343$ y A.M.S. ${ }^{9}$.D. ${ }^{9}$.. : LA. 1510 , sesión del 15 de enero. 
sobre todo por los períodos de ayuno que marcaba el calendario cristiano. El pescado de mar, congrio, morena y sardinas fundamentalmente, se traía incluso de Galicia, pero sobre todo de puertos más cercanos del Cantábrico. En efecto, en 1510, uno de los arrendatarios de las tiendas de Santo Domingo de la Calzada es un vecino de Bilbao llamado Fernando de Yanguas. Personaje que un año antes se había encargado de abastecer de pescado la tienda de la villa de Haro ${ }^{127}$.

En algunas ocasiones los acuerdos para el establecimiento de los "obligados" no eran fáciles de lograr, como queda puesto de manifiesto en los Libros de actas municipales de la villa de Haro ${ }^{128}$. No obstante, los concejos velaban por el cumplimiento de su "obligación" de abastecer de alimento, especialmente de carne, a la población. De ahí los quejas realizadas por el concejo de Logroño y sus carniceros en 1490 y 1491, porque el Capitán general de la frontera, Juan de Ribera, había puesto en la ciudad otro carnicero para abastecer a su Capitanía ${ }^{129}$. El mantenimiento del carácter público de estos establecimientos comerciales permitía a las autoridades concejiles controlar los precios establecidos, los pesos y medidas, las condiciones en que se vendía la mercancía, así como el pago de los impuestos indirectos ${ }^{130}$. Por ello los concejos perseguían las ventas clandestinas, multando a todos aquellos vecinos que no respetaran las disposiciones concejiles en esta materia, y vendieran productos alimenticios como la carne de forma privada, sin consentimiento del concejo ${ }^{131}$. Aún así, se seguian produciendo irregularidades, y en 1508 las autoridades municipales de Santo Domingo de la Calzada instaban al arrendatario de la carnicería, a que llevara a matar todo el ganado a la carnicería de la ciudad, pues se tenía constancia de que parte lo vendía a carnicerías de otros lugares ${ }^{132}$.

127 A.M.S. ${ }^{\circ} .^{\circ}$ C. ${ }^{2}$ : LA. 1510, sesión del 15 de enero y mi Tesis Doctoral: La sociedad altorriojana..., o.c., p. 386.

${ }_{128}$ "Por quanto estaban en debate con Juan Garçia de Brinnas çerca del cortar de la cabeça e de otras condiçiones algunas que al pueblo pertenesçian e porque al presente se non podia el sennor conçeio conçertar con el dicho Juan Garçia, mandaron e dieron cargo e poder al alcalde e regidores para que ellos se ayan de igualar lo mejor que Dios les ayudare con el dicho Juan Garçia" (A.M.H.: LA. 1465, sesión de concejo amplio del 7 de marzo).

129 A.G.S.: R.G.S., fols. 341 (15-VIII-1490) y 173 (24-IX-1491).

130 Fco. Javier GoicoleA JULIÁN, «Finanzas concejiles..., o.c.

131 Me remito a mi Tesis Doctoral: La sociedad altorriojana..., o.c., p. 335. La persecución del fraude por parte de las autoridades concejiles también se constata en núcleos urbanos como Burgos, Cuenca, Zamora o Toledo (Juan Antonio Bonachía HERnANDo, "Abastecimiento urbano..., o.c., pp. 85-162, Manuel Fernando LAdERO QUESADA, La ciudad de Zamora..., o.c., pp. 54-84, Yolanda Guerrero Navaraete y José María Sanchez Benito, Cuenca en la Baja Edad Media..., o.c. pp. 190-195, Ricardo IzQUIERdo Benito, "La actividad comecial en Toledo..., o.c., pp. 137-157).

132 A.M.S. ${ }^{9}$ D. ${ }^{9}$.C. ${ }^{\mathrm{a}}$ : LA. 1508 , sesión del 13 de julio. 
Tabla IV. Contratos para servir la carnicería y las tiendas de Santo Domingo de la Calzada en 1510

\begin{tabular}{|c|c|c|c|c|}
\hline & TITULARES & DURACIÓN & PRODUCTOS & PRECIOS \\
\hline CARNICERÍA & JUAN GARCÍA & $\begin{array}{c}\text { DESDE EL DÍA } \\
\text { DE PASCUA } \\
\text { DE FLORES } \\
\text { HASTA EL DÍA DE } \\
\text { CARNESTOLENDAS } \\
\text { DE } 1511 \\
\text { HASTA EL DÍA } \\
\text { DE SAN JUAN } \\
\text { DOS BANCOS } \\
\text { DE CARNERO, } \\
\text { Y DEL DÍA DE SAN } \\
\text { JUAN EN ADELANTE } \\
\text { UN BANCO DE } \\
\text { CARNERO Y OTRO } \\
\text { DE VACA }\end{array}$ & $\begin{array}{l}\text { CARNERO } \\
\text { VACA } \\
\text { OVEJA } \\
\text { CABRÓN }\end{array}$ & $\begin{array}{l}\text { CUARTA DE } \\
\text { CARNERO } \\
12 \text { MRS. } \\
\text { CUARTA DE } \\
\text { VACA } 11 \text { MRS. } \\
\text { CABEZA DE } \\
\text { CARNERO } \\
3 \text { MRS. } \\
\text { ASADURA } \\
5 \text { MRS. } \\
\text { PAR DE } \\
\text { TURMAS } 4 \text { MRS. }\end{array}$ \\
\hline TIENDAS & $\begin{array}{c}\text { FERNANDO } \\
\text { DE YANGUAS } \\
\text { JUAN DE } \\
\text { ALESANCO } \\
\text { TERESA DE } \\
\text { HERRERA }\end{array}$ & $\begin{array}{l}\text { DESDE EL DÍA DE } \\
\text { CARNESTOLENDAS } \\
\text { EN UN AÑO } \\
\text { DOS TIENDAS } \\
\text { TODO EL AÑO }\end{array}$ & $\begin{array}{l}\text { PESCADO } \\
\text { CONGRIO } \\
\text { MORENA } \\
\text { SARDINAS }\end{array}$ & $\begin{array}{l}\text { LIBRA DE } \\
\text { CONGRIO } \\
18 \text { MRS. } \\
\text { LIBRA DE } \\
\text { MORENA } \\
15 \text { MRS. } \\
\text { LIBRA DE } \\
\text { PESCADO } \\
\text { REMOJADO } \\
8 \text { MRS. } \\
\text { LIBRA DE } \\
\text { PESCADO } \\
\text { SEÇIAL } 11 \text { MRS. } \\
\text { UN PAR DE } \\
\text { SARDINAS } \\
\text { BLANCAS Y } \\
\text { ARENCADAS } \\
\text { 2MRS. }\end{array}$ \\
\hline
\end{tabular}

Fuente: A.M.S. ${ }^{8 D}{ }^{8}$ C. : L.A. 1510.

Sin duda, una de las principales preocupaciones de los concejos era la fijación de los precios, pues se trataba de conseguir alimentos suficientes, pero también que estuvieran al alcance de la mayoría del vecindario. En definitiva, tal y como afirma Juan Antonio Bonachía Hernando en su estudio sobre el abastecimiento y comercialización de carne en la ciudad de Burgos, "la tasación de precios es una garantía 
de paz social» ${ }^{133}$. En efecto, la sensibilidad de los sectores sociales populares de los núcleos urbanos altorriojanos ante las fluctuaciones del precio de la carne, queda puesta de manifiesto en Haro y en Logroño. En Haro, en 1471, la comunidad vecinal representada por los cuadrilleros, se quejará ante los oficiales del Regimiento de la subida del precio de la carne que habían acordado con el carnicero, logrando anularla ${ }^{134}$. En Logroño, en 1490 , se llegarán a generar "alborotos" contra los carniceros y los oficiales que habían arrendado la carnicería, por considerar excesivos los precios establecidos en el contrato ${ }^{135}$. Lo cierto es que los abusos fueron frecuentes, sobre todo en los años en que había dificultades para arrendar las carnicerías, situación que era aprovechada por determinados vecinos, que sabedores de la imperiosa necesidad de abasto del núcleo urbano, se comprometían a traer ganado para matar en las carnicerías, vendiendo la carne posteriormente a precios elevados ${ }^{136}$.

Las autoridades concejiles se preocupaban de conocer los precios de la carne y de los demás alimentos en los principales mercados más próximos. De esta forma, sabemos que el concejo de Haro enviaba mensajeros con este motivo a Burgos, Vitoria, Briviesca, Belorado, Logroño, Nájera o Santo Domingo de la Calzada. Era el mercado de esta ciudad el que tenían más en cuenta los gobernantes de Haro, de tal forma que en un gran número de los contratos de obligación que se han conservado, se estipulaba que la puja de los precios de la carne debía ser "en la manera que se obligare el carniçero de Santo Dorningo" ${ }^{137}$. No obstante, también se producía la situación viceversa, y tenemos constancia de la llegada a la villa de Haro de mensajeros procedentes de Santo Domingo de la Calzada, con objeto de conocer los precios de venta del vino en la villa ${ }^{138}$.

Igualmente contamos con informaciones en este sentido procedentes de la ciudad de Nájera, cuyo concejo enviará mensajeros a Burgos, pero también a la propia villa de Haro ${ }^{139}$. En estos casos no sólo para traer testimonios de los precios de venta, sino incluso para conseguir carniceros

133 Juan Antonio Bonachia Hernando, "Abastecimiento urbano..., o.c., p. 140.

134 A.M.H.: LA. 1471, sesión de concejo amplio del 22 de julio.

135 Ernesto García Fernández y José Ramón díaz de DuRANa, “Las actividades económicas en Logroño..., o.c., p. 10 y Margarita CANTERA MONTENEGro, «La hacienda..., o.c., pp. 511-524.

${ }_{136}$ Me remito a mi Tesis Doctoral: La sociedad altorriojana..., o.c., pp. 329-336.

137 lbidem., p. 331.

138 A.M.S. ${ }^{\circ}$ D. C. : LA. 1513 , tenemos constancia de la presencia de estos mensajeros en la villa de Haro el 15 de septiembre, el 1 de octubre y el 1 de diciembre.

139 "A honse dias del dicho mes fue Juan de Aragon a Pero Sarmyento e dende fue a Haro con otra carta a saber commo balian sardina e pescado, mandaronle dar dies maravedis" (A.M.N. LC. 1439-40, cuenta de gastos en dinero). 
que dieran abasto en la ciudad. Así ocurrió en 1440, cuando el concejo de Nájera envió un mensajero por este motivo a la ciudad de Burgos, mientras que uno de sus alcaldes acudía a la villa de Briones con la misma finalidad de "buscar" carniceros ${ }^{140}$. Esta dificultad para conseguir carniceros y personas que sirviesen las tiendas también se dio en la villa de Haro, como consecuencia de la alta tasación de las alcabalas de la carnicería y de la buhonería en algunos años, de tal forma que "non podian aver ofiçiales que serbiesen los dichos ofiçios de tiendas e carniçeria e estaban sin provisiones" ${ }^{141}$. Por ello, al concejo no le quedaba más remedio en algunos años que llegar a acuerdos con los arrendatarios de las alcabalas, por los cuales se hacía con el control de la percepción de las mismas, con objeto de asegurar el abasto de la villa y evitar la conflictividad social a que esta situación daba lugar ${ }^{142}$.

En nuestro estudio sobre la villa de Haro, hemos podido comprobar cómo el sistema contractual que establecía el concejo con los carniceros y los tenderos, varió en los primeros años del siglo XVI. En efecto, los contratos tradicionales del siglo $\mathrm{xV}$, a los que ya hemos hecho referencia, fueron sustituidos por un sistema de pujas y subasta muy similar al utilizado para el arrendamiento de las rentas concejiles. El proceso seguido era el siguiente: a principios de cada año las autoridades municipales ponian a subasta la carnicería y la tienda de la villa. Los interesados ofertaban unos precios determinados de venta de la carne y de los demás productos, que el concejo se encargaba de bajar lo más posible mediante la concesión de incentivos o prometidos de dinero, de tal forma que cuando el concejo consideraba que la puja de los precios era suficientemente baja, la hacia pública mediante el pregonero, esperando un tiempo prudencial ante la posible llegada de un nuevo licitador. Si esto no sucedía se procedía directamente al remate, que era realizado públicamente por el pregonero delante de la casa de la Primicia ${ }^{143}$. En la ciudad de Santo Domingo de la

140 "A dose dias del dicho mes fue Pero Lopes de Haro a Burgos por mandado de los alcaldes a saber a commo valia la carne e a que presçio e si se podrian aver carniçeros...", "este dia fueron Diego Lopes alcalde e Juan de Arençana con el a Briones a buscar carniçeros..." (A.M.N.: LC. 143940 , cuenta de gastos en dinero). Una práctica que también fue seguida en otros núcleos urbanos, pues el concejo de Burgos también recurrió a lo largo del siglo XV a buscar carniceros en otras villas y ciudades (Juan Antonio BONACHIA HERNANDO, "Abastecimiento urbano..., o.c., pp. 85-162).

141 A.M.H.: LA. 1470, sesión de concejo restringido del 7 de abril.

142 Me remito a mi Tesis Doctoral: La sociedad altorriojana...o.c., pp. 620-627. Práctica que también fue seguida por el concejo de Burgos (Yolanda GuERRERo NAVARRETE, “Fiscalidad regia y poder municipal en Burgos (1453-1476)", En la España Medieval V (1986), pp. 481-500).

143 Me remito a mi Tesis Doctoral: La sociedad altorriojana..., o.c., pp. 336 y 342-343. Este sistema también fue utilizado en Burgos a partir de 1427, aunque se usará de forma escasa e irregular (Juan Antonio BONACHÍA HERNANDO, “Abastecimiento urbano..., o.c., pp.108-124). 
Calzada, a inicios del siglo XVI, comprobamos que se utilizaban los dos procedimientos contractuales para la provisión de la carnicería y de las tiendas: obligados y subasta. En efecto, también en este núcleo urbano constatamos la realización de subastas en las que los licitadores pujaban a la baja los precios de los diferentes productos alimenticios: "dixeron a altas boçes sy abia alguno que quisyese dar alguna baxa a la dicha carniçeria, que daban por la cuarta del carnero a treçe maravedis e de la cuarta de la baca a nuebe maravedis e medio, e asy se publico a altas boçes muchas beçes e non se allo quien mas baxa diese, e ansy luego non abiendo quien mas baxase en los dichos preçios de baca e carnero, la dicha carneçeria se remato en Juan de Ameyugo" 144.

Los concejos también intervenían en la comercialización y control de otros productos alimenticios que se vendían en los núcleos urbanos, tales como el cereal, los productos hortofrutícolas, el pescado de río o el pan. En Santo Domingo de la Calzada, las autoridades municipales establecen contratos con las "panaderas" para la provisión de pan, pregonando la apertura del plazo de licitación del abasto por todos los cantones de la ciudad ${ }^{145}$. En Haro, su concejo concede exenciones y privilegios a los mercaderes que acuden al mercado de la villa a vender cereal, establece contratos de obligación con panaderos y panaderas para provisión de la villa, persigue las reventas y se encarga de asegurar que el mercado esté bien abastecido de hortalizas, fruta y pescado de río. Igualmente, controla todo lo rigurosamente que puede el proceso de venta de estos productos: "mandaron que ninguno non fuese osado de vender pescado ninguno si non a los preçios siguientes e que todo el pescado que se bendiere que non sea osado de lo bender si non en la plaça segund costunbre de la dicha villa» ${ }^{146}$.

También constatamos el ejercicio de este control por parte del concejo de Nájera, a través de los dos fieles que eran elegidos cada año. Estos fie-

144 A.M.S. ${ }^{\circ}$ D. ${ }^{\circ}$ C. : : LA. 1512, sesión del 25 de febrero.

145 "Mandaron los dichos sennores que se pregone que las panaderas que se quisieren obligar que bengan a obligarse ya adelante para dya de Sant Vartolome adelante...se apregono publicamente por todos los cantones lugares acostumbrados de esta çiudad por mandado de los senores corregidor e regydores e ayuntamiento que todas las panaderas que se quysieren oblygar de serbir a la çiudad desde el dia de Sant Bartolome primero que byene de este presente anno para adelante fasta ser cumplido un anno que bengan a los sennores justiçia e regidores e que la daran a quien en myjor preçio e mas honra a la çiudad yçyese. Lo qual se apregono en el canton de la calleja de Barryo Biejo e en el canton del Mercado e en el canton de la plaça do Myguel de Oçio e en el canton de Marburguete do Juan de Salçedo e en el canton de la calleja de Barrio Nuebo e en el canton del Pynal e en el canton del pozo de la Puebla donde Sebastian de Ozio y en el canton de la Parrilla (A.M.S. ${ }^{9}$ D. ${ }^{8}$ C. ${ }^{2}$ : LA. 1508 , sesión del 18 de julio).

${ }_{146}$ A.M.H.: LA. 1477, sesión de concejo restringido del 7 de junio. 


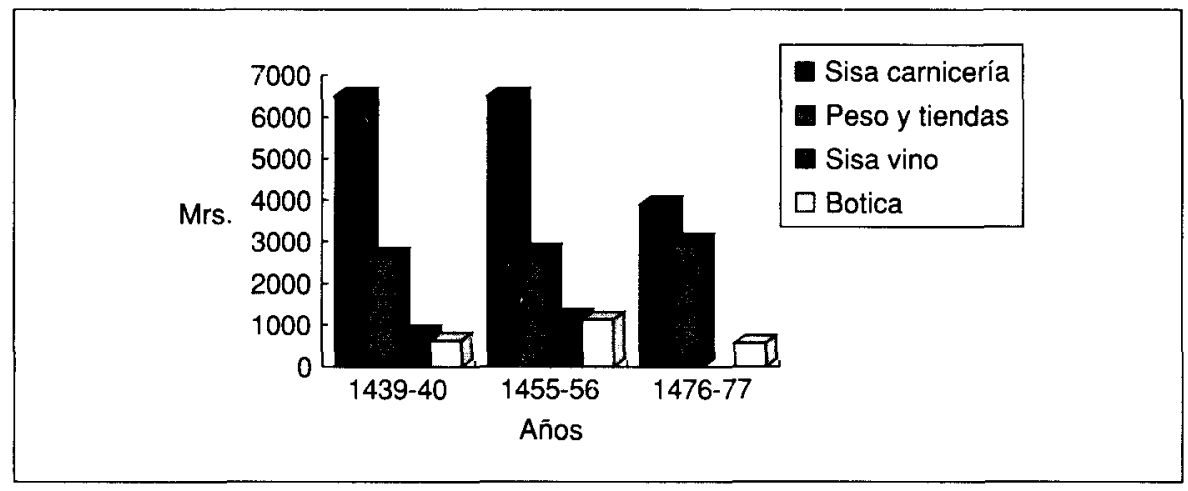

Fuente: A.M.N.: Libros de cuentas concejiles.

Gráfico IX. Ingresos del Concejo de Nájera procedentes de las rentas de la sisa de la carnicería, peso y tiendas, sisa del vino y botica.

les se encargaban de controlar los productos que se vendían en las tiendas, en la carnicería y en el mercado, asegurándose de que fueran de calidad y de que no estuvieran en mal estado, e igualmente se encargaban de vigilar para que los comerciantes respetaran los precios establecidos, así como los pesos y medidas reglamentarios ${ }^{147}$. La actuación de los fieles también la documentamos en Santo Domingo de la Calzada a inicios del siglo xvı. En efecto, a través de los Libros de actas municipales, podemos comprobar cómo los fieles inspeccionaban las tiendas de la ciudad, controlando el estado y la calidad de los productos que se vendían en ellas: "fueron a casa de la dicha e le dixieron que les mostrase las candelas e açeite e pabilo que tenia, la qual les amostro un castillo de candelas y los pabilos descabos y un jubillo descabos y otro de estopa y dize ocho barillas de candelas, los pabilos descabos puestos a donde se haçian e abian de hazer. E visto las dichas candelas ser fechas del dicho pabilo descabos mandaron a los fieles que las tomasen e las levasen con ellos, e asy mysmo les amostro la haçeyte y allaron ser buena" ${ }^{148}$.

Pero, además de los productos alimenticios, los concejos también regulan y controlan las compraventas de productos artesanales que se realizan en el mercado. Las diferentes alcabalas que se recaudan en la villa de Haro: Buhonería, Lana y Lino, Zapatería o Paños, son un fiel reflejo de

147 En el Libro de cuentas de 1439-40 se asientan las penas impuestas por los fieles del concejo de Nájera por estos motivos (A.M.N.: LC. 1439-40, cuenta de ingresos en dinero).

${ }_{148}$ A.M.S. ${ }^{9}$ D. ${ }^{9}$. : : LA. 1512 , sesión del 27 de julio. 
estas actividades comerciales ${ }^{149}$. En este sentido, la creciente presión fiscal indirecta de finales de la Edad Media repercutirá en el mercado local. En 1511, un mercero informaba a las autoridades municipales de Santo Domingo de la Calzada, de su intención de abrir una tienda de mercería en la ciudad, mostrando su preocupación por la tasación de la alcabala ${ }^{150}$. En la ciudad de Logroño, la creciente presión fiscal impuesta por el concejo sobre las ventas de paños realizadas por los mercaderes y traperos, dará lugar a protestas en el año 1484. También fue objeto de control en esta ciudad la actividad de los cambistas, a quienes los Reyes Católicos ordenaron en 1495 que se colocaran en lugares públicos para realizar su trabajo, pues acostumbraban a ejercerlo privadamente en sus casas con objeto de no pagar ningún derecho a la hacienda concejil ${ }^{151}$. Los concejos altorriojanos también cobraban derechos derivados de la correduría. En efecto, muchas transacciones, sobre todo en lugares y días de mercado, entre vecinos y forasteros, se efectuaban mediante la intermediación de los corredores. En los casos de Haro y de Nájera constatamos que sus haciendas concejiles ingresaban dinero procedente de la renta de la correduría ${ }^{152}$.

En definitiva, el control de las actividades comerciales realizadas en los núcleos urbanos, representa una considerable fuente de ingresos para las mermadas haciendas municipales de finales de la Edad Media ${ }^{153}$. En efecto, un número importante de los gravámenes impuestos por las autoridades concejiles altorriojanas, afectan a las transacciones comerciales realizadas en las carnicerías, tiendas, tabernas, en el propio mercado, etc. ${ }^{154}$. En Haro, en los años finales del siglo XV, entre las nuevas imposiciones fiscales concejiles, destacan la renta del "peso del pescado fresco" y la renta del "pan cocido" O "banco de las panaderas" ${ }^{155}$. Pero, además, las sisas extraordinarias impuestas sobre los productos de primera necesidad como el pan, la carne, el pescado, el aceite y el vino, se convierten

\footnotetext{
149 Me remito a mi Tesis Doctoral: La sociedad altorriojana..., o.C., pp. 615-620.

150 A.M.S. ${ }^{9}$ D. ${ }^{\circ}$ C. ${ }^{2}:$ LA. 1511 , sesión del 23 de agosto.

151 Margarita Cantera MONTENEGRO, "La hacienda concejil..., o.c., pp. 511-524.

152 Me remito a mi Tesis Doctoral: La sociedad altorriojana..., o.c., p. 564. El concejo de Nájera ingresó seiscientos maravedís procedentes de la renta de la correduría en los ejercicios 143940 y $1476-77$.

153 Miguel Ángel Ladero QueSAdA, "Las haciendas concejiles en la Corona de Castilla..., o.c., pp. 9-71.

154 FCo. Javier GoICOLEA JULIÁN, “Finanzas concejiles..., o.c. El cabildo calceatense tenía el privilegio de poder cobrar la mitad de la renta del mercado que se celebraba en Santo Domingo de la Calzada (Ciriaco LOPEZ DE SILANes y Eliseo SAInz RIPA, Colección Diplomática Calceatense. Archivo Catedral (Años 1125-1397).., o.c., doc. $\mathrm{n}^{2} 87$ ).

155 Me remito a mi Tesis Doctoral: La sociedad altorriojana..., o.c., pp. 564-565.
} 
en un procedimiento de financiación concejil que se generaliza a finales de la Edad Media en los núcleos urbanos altorriojanos ${ }^{156}$.

La potenciación dei mercado constituirá, lógicamente, un objetivo prioritario de la política económica de los concejos. En efecto, Logroño obtendrá un privilegio del monarca Enrique IV, en el que concede a la ciudad un mercado franco de alcabala un día de la semana, concretamente el martes. Privilegio que será confirmado posteriormente, en 1486, por los Reyes Católicos ${ }^{157}$. También a finales del siglo $\mathrm{xV}$, en la ciudad de Santo Domingo de la Calzada, su concejo establecerá un mercado franco los miércoles ${ }^{158}$. La política de concesión de exenciones y privilegios con objeto de potenciar el mercado, es puesta en práctica igualmente por el concejo de Haro a lo largo del siglo Xv. Para ello no duda en enviar mensajeros a las ciudades y villas comarcanas con objeto de pregonar las exenciones que recibirán los mercaderes que vengan a vender sus productos al mercado de Haro ${ }^{159}$. Su concejo trata de potenciar especialmente los mercados de cereal que se celebran los martes y los viernes, y para ello exime del impuesto de la alcabala a los comerciantes que traen trigo, cebada, avena y centeno a la villa ${ }^{160}$.

\section{CONCLUSIÓN}

Desde su fundación, y a lo largo de los siglos medievales, en los núcleos urbanos altorriojanos se despliegan toda una serie de actividades económicas, que son el soporte y el sustento de su sociedad. Entre éstas, las actividades económicas agropecuarias ocupan un papel fundamental. En efecto, el trabajo de la tierra representa la actividad preponderante, adquiriendo especial relevancia el cultivo de la vid, que se va convirtiendo a finales de la Edad Media en uno de los pilares de la economía del mundo urbano de la comarca altorriojana. Junto a la agricultura, un porcentaje importante de la población ciudadana complementa sus recursos económicos con la ganadería y con la explotación de los recursos forestales y fluviales.

\footnotetext{
156 FCO. Javier GoICOLEA JULIÁN, "Finanzas concejiles..., o.c.

157 Margarita Cantera Montenegro, "La hacienda concejil..., o.c., pp. 511-524.

158 A.G.S.: R.G.S., fol. 78 (1-XI-1497) y fol. 125 (8-I-1498).

159 «Fue a faser pregonar por las villas de Belforado e Çereso e Redesilla e Grannon que traxiesen pan a bender e que serian quitos de alcabala" (A.M.H.: LC. 1455, cuenta de gastos en dinero).

${ }_{160}$ Me remito a mi Tesis Doctoral: La sociedad altorriojana..., o.c., pp. 343-346.
} 
Pero, además del sector primario, también se desarrollan desde la época foral los sectores artesanal y comercial, incentivados por la positiva influencia del Camino de Santiago, y por las exenciones y privilegios concedidos por los diferentes monarcas. No obstante, la crisis del siglo xIV y el cambio del eje comercial traerán importantes consecuencias, debiendo de adecuarse las ciudades y villas altorriojanas a las nuevas condiciones de la realidad económica castellana. A finales de la Edad Media, los concejos, en el marco de una política proteccionista, tratan de potenciar las actividades artesanales con objeto de asegurar el autoabastecimiento de los núcleos urbanos. Se desarrolla de esta manera un sector artesanal y comercial, que va a ser capaz de abastecer a las necesidades locales de aquellos productos de que carecían o cuya calidad era menor. Sin embargo, los datos que poseemos nos indican que estas ciudades y villas se encuentran en una fase menos brillante que la que tuvieron en los siglos de máximo auge de la Ruta Jacobea. La comparación de los padrones conservados para la ciudad de Santo Domingo de la Calzada resulta bastante significativa. En efecto, proporcionalmente al número de vecinos, el porcentaje de población artesana empadronada en el siglo xIII es superior al de inicios del siglo xvl.

\section{ABREVIATURAS UTILIZADAS}
A.H.N.:
Archivo Histórico Nacional.
A.G.S:
Archivo General de Simancas.
R.G.S.:
Registro General del Sello.
A.R.CH.V.: Archivo de la Real Chancillería de Valladolid.
A.M.L.:
Archivo Municipal de Logroño.
A.M.S. ${ }^{\circ}$ D. ${ }^{\circ}$ C. ${ }^{a}$ : Archivo Municipal de Santo Domingo de la Calzada.
A.M.H.:
Archivo Municipal de Haro.
A.M.N.:
Archivo Municipal de Nájera.
L.A.:
Libro de actas.
L.C.:
Libro de cuentas.
L.B.P.V.H.: $\quad$ Libro Becerro de los privilegios de la villa de Haro. 